\title{
Efficient Removal of Organic Dyes and Lead lons With Eco-friendly Prepared Zinc Oxide Nanoparticles From Water
}

\section{Mohamed Abdel Salam ( $\sim$ masalam16@hotmail.com )}

Department of Chemistry, Faculty of Science, King Abdulaziz University, P.O Box 80200-Jeddah 21589,

Saudi Arabia

\section{Maymounah Alharthi}

King Abdulaziz University

lqbal Ismail

King Abdulaziz University

\section{Stefano Bellucci}

National Institute of Nuclear Physics, National Laboratories of Frascati, I-00044 Frascati, Italy

\section{Research Article}

Keywords: ZnO NPs, Azo dye, Environmental remediation, Lead ion

Posted Date: January 14th, 2021

DOI: https://doi.org/10.21203/rs.3.rs-142658/v1

License: (c) (i) This work is licensed under a Creative Commons Attribution 4.0 International License. Read Full License 
Efficient removal of organic dyes and lead ions with eco-friendly prepared zinc oxide nanoparticles from water

Maymounah N. Alharthi ${ }^{a, b}$, Iqbal Ismail $^{a}$, Stefano Bellucci ${ }^{c}$, Mohamed Abdel Salam $^{a *}$

${ }^{a}$ Department of Chemistry, Faculty of Science, King Abdulaziz University, P.O Box 80200-Jeddah 21589, Saudi Arabia

${ }^{\mathrm{b}}$ Department of Chemistry, College of Science, Princess Nourah bint Abdulrahman University, P.O Box 84428-Riyadh 11671, Saudi Arabia

c National Institute of Nuclear Physics, National Laboratories of Frascati, I-00044 Frascati, Italy

\section{*Corresponding author}

Tel.: +966-541886660; Fax: +966-2-6952292

masalam16@hotmail.com 


\begin{abstract}
In this research work, different $\mathrm{ZnO}$ NPs were prepared via eco-friendly green route using Ziziphus jujuba leaves extract assisted by microwave. Eco-friendly prepared $\mathrm{ZnO}$ NPs characterized by different techniques, and the results confirmed the preparation of hexagonal wurtzite $\mathrm{ZnO}$ nanoparticles with different particle sizes. The prepared $\mathrm{ZnO}$ NPs were then used for the adsorption and removal of two different azo dyes; methyl orange (MO), and methylene blue (MB), as well as toxic $\mathrm{Pb}(\mathrm{II})$ ions, from a model solution and real samples. Influence of experimental conditions was explored, and the results showed that most of the $\mathrm{MB}, \mathrm{MO}$ and $\mathrm{Pb}$ (II) could be removed from the model solution within few minutes, at ambient conditions using $15 \mathrm{mg} \mathrm{ZnO}$ NPs. The removal of the MB, $\mathrm{MO}$ and $\mathrm{Pb}$ (II) using $\mathrm{ZnO}$ NPs was studied kinetically and thermodynamically, and the results showed that the experimental data were best fitted using the pseudo-second-order kinetic models. The thermodynamics study showed that the process was spontaneous, with exothermic nature. Finally, the prepared $\mathrm{ZnO}$ NPs were used for the removal of MB, MO and $\mathrm{Pb}(\mathrm{II})$ in real wastewater sample, and high removal efficiency was presented.
\end{abstract}

Keywords: ZnO NPs; Azo dye; Environmental remediation; Lead ion 


\section{Introduction}

Environmental remediation of polluted environment by adsorption is as an effective process because it does not produce any harmful by-products as well as the regeneration ability of both solid adsorbent and pollutants [1]. Currently, the preparation of novel robust adsorbents with high efficiency for the removal of different classes' pollutants; organic and inorganic, from polluted water is the focus of different research studies. The exceptional characteristics of nanomaterials have motivated the researchers' world-wide to prepare different nanostructures to be used as adsorbents. Among these nanomaterials zinc oxide nanoparticles ( $\mathrm{ZnO} \mathrm{NPs}$ ) is considered to be one of the most used nanomaterials. ZnO NPs featured by the purity of their structure and the well-designed composition, large specific surface area and small, hollow, and layered structures, which has been used in different applications, such as corrosion inhibition [2], biomedical [3-8], food packaging [9], energy [10], textiles [11], antibacterial [12], water treatment through photocatalytic process $[13,14], \mathrm{CO}_{2}$ conversion $[15,16]$, and adsorption of organic[17], and inorganic pollutants [18].

Unfortunately, the preparation of ZnO NPs using the wet chemical routes usually involve the use of different chemical compounds through controlled precipitation, sol-gel method, solvothermal and hydrothermal method which involves multistep processes, long reaction times and use of various hazardous chemicals as well as the production of a huge amount of harmful byproducts, as well as hazardous chemical waste [19]. Nowadays, there are a new trend focus on the application of more eco-friendly green methods based on the use of plants, fungus, bacteria, and algae, which characterized with the replacement of the hazardous chemicals with green extract and the eco-friendly prepared $\mathrm{ZnO}$ NPs were characterized with comparable, and most of the times higher activities [20-23]. Furthermore; as it mentioned previously, the use of the chemical routes for the preparation of metal oxide NPs, required long time, hence, microwave-assisted route attracted the 
attention of the researcher due to the high preparation rate, resulting from the superior to traditional heating as a results of the volumetric heating as the microwaves usually supply energy by penetrating the material, which allows the reaction to be completed in minutes or even seconds $[24,25]$. For example, ZnO NPs prepared by microwave-assisted showed outstanding colloidal stability, more uniform size, shape and chemical surface properties compared with the traditional heating approach [26-28]. The combination of both ecofriendly and microwave-assisted route for the preparation of $\mathrm{ZnO}$ NPs is still scarce in literatures [29]. It is hypothesized that the eco-friendly preparation of ZnO NPs assisted by microwave will produce nanoparticles wit extraordinary activity compared with traditionally prepared ones.

The objective of this research was to prepare $\mathrm{ZnO}$ NPs via eco-friendly green route using Ziziphus jujuba leaves extract assisted by microwave. The morphological characterization of prepared ZnO NPs; traditional ZnO NPs ( ZnO NPs), green ZnO NPs (G ZnO NPs), and the microwave assisted green $\mathrm{ZnO}$ NPs (MWG ZnO NPs), was performed by transmittance electron microscopy. X-ray diffraction was used to examine the chemical and crystal structure of the prepared $\mathrm{ZnO}$ NPs, as well as of surface area analysis was applied to determine the textural properties. The prepared $\mathrm{ZnO}$ NPs were then used for the adsorption and removal of two different azo dyes; methyl orange (MO) as an example of anionic dye, and methylene blue (MB); as an example of cationic dye, as well as toxic $\mathrm{Pb}(\mathrm{II})$, from water samples, as the removal of both cationic and anionic dyes in addition to heavy metals are not readily achieved simultaneously. The influence of different experimental factors may affect the removal was optimized. The kinetics and thermodynamics of the $\mathrm{MO}, \mathrm{MB}$, and $\mathrm{Pb}[\mathrm{II}]$ ions removal using $\mathrm{ZnO}$ NPs was explored for the understanding of the remediation process spontaneity.

\section{Experimental}




\subsection{Chemicals}

All chemicals (analytical grade) were purchased from Sigma-Aldrich, and the solutions were prepared by deionized water.

\subsection{Methods}

\subsubsection{Ziziphus jujuba leaves extract (Sidr) preparation}

Fresh and healthy leaves of Ziziphus jujuba (Sidr) were collected from Jeddah, Saudi Arabia, on October 2019. The leaves were washed very well with tap water, then with deionized water and were dried on air at ambient temperature, then the cleaned leaves were chopped and grounded, and $5.0 \mathrm{~g}$ was added to a $100 \mathrm{ml}$ of deionized water in a beaker. The mixture was boiled for 20.0 minutes, then cooled to room temperature and was centrifuged at 3,600 rpm for 30 minutes, till a clear filtrate was obtained, and stored at $4{ }^{\circ} \mathrm{C}$.

\subsubsection{Traditional ZnO NPs (T ZnO NPs) preparation}

Aqueous solution of Zinc acetate $(0.2 \mathrm{M})$ and the solution $(0.5 \mathrm{M})$ of $\mathrm{NaOH}$ were prepared with deionized water. The $\mathrm{NaOH}$ solution was added drop by drop using a burette to the zinc acetate solution at room temperature under vigorous stirring, which resulted in the formation of the white precipitate of zinc hydroxide. The white precipitate of the zinc hydroxide separated by centrifugation at $3900 \mathrm{rpm}$ for $30 \mathrm{~min}$ and washed three times with distilled water, followed by ethanol. The obtained product was dried at $60{ }^{\circ} \mathrm{C}$ in air atmosphere for $24 \mathrm{~h}$.

\subsubsection{Green $\mathrm{ZnO}$ NPs (G ZnO NPs) preparation}

Aqueous solution of Zinc acetate $(0.2 \mathrm{M})$ and the solution $(0.5 \mathrm{M})$ of $\mathrm{NaOH}$ were prepared using the Ziziphus jujuba leaves extract. The $\mathrm{NaOH}$ solution; in the extract, was added drop by drop using a burette to the zinc acetate solution; in the extract, at room temperature under vigorous stirring, which resulted in the formation of the light-brown precipitate of zinc hydroxide. The light-brown precipitate was separated by centrifugation at $3900 \mathrm{rpm}$ 
for $30 \mathrm{~min}$ and washed three times with distilled water, followed by ethanol. The obtained product was dried at $60{ }^{\circ} \mathrm{C}$ in air atmosphere for $24 \mathrm{~h}$ to convert the $\mathrm{Zn}(\mathrm{OH})_{2}$ to $\mathrm{ZnO}$ NPs. 2.2.4. Preparation of microwave-assisted green ZnO NPs (MWG ZnO NPs)

Aqueous solution of Zinc acetate $(0.2 \mathrm{M})$ and the solution $(0.5 \mathrm{M})$ of $\mathrm{NaOH}$ were prepared using the Ziziphus jujuba leaves extract. The $\mathrm{NaOH}$ solution; in the extract, was added drop by drop using a burette to the zinc acetate solution; in the extract, at room temperature under vigorous stirring, which resulted in the formation of the light-brown precipitate of zinc hydroxide. The result solution was treated by $400 \mathrm{~W}$ microwave for 5 minutes to convert the $\mathrm{Zn}(\mathrm{OH})_{2}$ to $\mathrm{ZnO} \mathrm{NPs}$, then the precipitate was separated by centrifugation at $3900 \mathrm{rpm}$ for $30 \mathrm{~min}$ and washed three times with distilled water, followed by ethanol. The obtained product was dried at $60{ }^{\circ} \mathrm{C}$ in air atmosphere for $24 \mathrm{~h}$ to convert the $\mathrm{Zn}(\mathrm{OH})_{2}$ to $\mathrm{ZnO} \mathrm{NPs}$.

\subsection{Characterization methods}

X-ray diffraction (XRD) patterns were recorded for phase analysis and the measurement of crystallite size was performed on a Philips X-pert pro diffractometer. The instrument was operated at $40 \mathrm{~mA}$ and at $40 \mathrm{kV}$ on a $\mathrm{CuK} \alpha$ radiation and a nickel filter in the $2 \theta$ range from 2 to $80^{\circ}$ in steps of $0.02^{\circ}$, with a sampling time of one second per step. Estimation of the crystal size was done according to the Scherrer equation. The morphological structure of the prepared ZnO NPs were studied using FEI Quanta 250 field emission gun scanning electron microscope. The specific surface area of the ZnO NPs were estimated using the nitrogen adsorption/desorption isotherm at $77 \mathrm{~K}$, by NOVA3200e (Quantachrome, USA).

\subsection{Removal experiments}

ZnO NPs were added to $20 \mathrm{~mL}$ contains $\mathrm{MO}(5.0 \mathrm{mg} / \mathrm{L}), \mathrm{MB}(5.0 \mathrm{mg} / \mathrm{L})$, and $\mathrm{Pb}(\mathrm{II})(500$ $\mathrm{mg} / \mathrm{L}$ ), followed by magnetic stirring, then the ZnO NPs was separated from the solution 
using centrifuge, followed by separation via Whatman ${ }^{\mathrm{TM}}$ filter paper \# 5 filtration, and the clear filtrate was collected for the analysis of the residual $\mathrm{MB}, \mathrm{MO}$ and $\mathrm{Pb}(\mathrm{II})$. The concentration of the residual MO, and MB dyes in each solution was measured using UVvis spectrophotometer (UV-1650 PC, CPS-240A SHIMADZU) at 464 and $670 \mathrm{~nm}$ as shown in Fig. 1, respectively. The residual $\mathrm{Pb}(\mathrm{II})$ ion concentration was then measured using Perkin Elmer optima 7000 DV inductively coupled plasma/optical emission spectrometer (ICP-OES). The percent removal $(\mathrm{R} \%)$ and capacity $\left(\mathrm{q}_{\mathrm{t}}\right)$ were using Equation (1) and Equation (2):

$$
\begin{aligned}
& \text { (1) } R \%=100 \times \frac{C_{0}-C_{t}}{C_{0}} \\
& \text { (2) } q_{t}=\left(C_{0}-C_{t}\right) \times \frac{V}{m}
\end{aligned}
$$

where $\mathrm{C}_{0}$ is the initial concentration per $(\mathrm{mg} / \mathrm{L}), \mathrm{C}_{\mathrm{t}}$ is the residual concentration $(\mathrm{mg} / \mathrm{L})$ after certain period of time, $\mathrm{m}$ is the mass of $\mathrm{ZnO} \mathrm{NPs}(\mathrm{g})$, and $\mathrm{V}$ is solution volume (L). All the experiments were conducted in triplicates, and the stated values were the average with less than $5 \%$ error.

\subsection{Real samples}

Seawater, tap water, and wastewater were used as the real samples. The seawater sample from the Red Sea (Jeddah, Saudi Arabia -latitude 21.518333, longitude 39.150677), tap water sample obtained from the laboratory after the tap water had been allowed to flow for ten minutes. All samples were filtered (45.0 $\mu \mathrm{m}$ Millipore filter paper) and preserved in the dark using Teflon bottles at $278 \mathrm{~K}$.

\section{Results and discussion}

\subsection{ZnO NPs characterization}


Figure 2 illustrates the XRD patterns of different prepared $\mathrm{ZnO}$ NPs; $\mathrm{T}$ ZnO NPs, G ZnO NPs, and MWG ZnO NPs. In general, for all prepared ZnO NPs, the characteristic peaks of $\mathrm{ZnO}$ NPs were identified from three main diffraction peaks at $2 \theta=31.73,34.38$, and $36.20^{\circ}$ that related to the (100), (002), and (101) hexagonal wurtzite $\mathrm{ZnO}$ crystal planes (JCPDS file no.36-1451), with different intensities. The ZnO NPs crystallite size as calcualted from the Scherer equation was $21.5,25.7,26.40 \mathrm{~nm}$, for T ZnO NPs, G ZnO NPs, and MWG ZnO NPs, respectively, indicating the increase in the crystallite size due to the thermal treatment via the microwave pathway, which characterized with the rapid, and high temperature compared with the traditional method. The increase in crystallite size with the microwave prepared ZnO NPs could be attributed to thermally promoted crystallite growth [30].

Scanning electron microscope images of the ZnO NPs; $\mathrm{T}$ ZnO NPs, G ZnO NPs, and MWG ZnO NPs are presented in Fig. 3, which shows that ZnO NPs exists in several sizes and shapes depends on the preparation method. For example, $\mathrm{T} \mathrm{ZnO}$ NPs sizes and in the form of irregular spherical particles with average particle size of $40 \mathrm{~nm}$, whereas the $\mathrm{G}$ ZnO NPs, and MWG ZnO NPs characterized with the irregular flake-shape composed of very small particles with an average particle size of $20 \mathrm{~nm}$, and $33 \mathrm{~nm}$, respectively. The small size of the $\mathrm{G} \mathrm{ZnO}$ NPs may be attributed to the presence of the Ziziphus jujuba leaves extract which act as capping agent, and prevent the agglomeration of the $\mathrm{ZnO}$ NPs. Also, the bigger particle size of the MWG ZnO NPs compared with the G ZnO NPs may be ascribed to the thermally promoted crystallite growth due to the fusion of the small particles as a results of the high temperature.

The specific surface areas of the $\mathrm{ZnO}$ NPs were calculated from the nitrogen gas adsorption/desorption isotherms at $77 \mathrm{~K}$ applying the BET equation, as shown in Fig. 4. The BET specific surface areas were $12.65,11.45$, and $11.44 \mathrm{~m}^{2} / \mathrm{g}$ for the $\mathrm{T} \mathrm{ZnO}$ NPs, G 
ZnO NPs, and MWG ZnO NPs, respectively, indicating surface area slight decrease upon the microwave treatment.

\subsection{Removal experiment}

The removal of two different azo dyes; $\mathrm{MO}$ and $\mathrm{MB}$, as well as toxic $\mathrm{Pb}(\mathrm{II})$, from a model solution using the different $\mathrm{T}$ ZnO NPs; ZnO NPs, G ZnO NPs, and MWG ZnO NPs, was performed and the results were presented in Fig. 5. The results revealed that the maximum removal of the $\mathrm{MB}, \mathrm{MO}$ and $\mathrm{Pb}(\mathrm{II})$ was obtained by the application of the MWG $\mathrm{ZnO}$ NPs, compared with the G ZnO NPs, and ZnO NPs. The removal efficacies were $78.03 \%$, $38.44 \%$, and $90.78 \%$ for the MB, MO and $\mathrm{Pb}(\mathrm{II})$, respectively, using MWG ZnO NPs, and these efficacies decreased to $71.96 \%, 32.53 \%$, and $79.60 \%$ for the $\mathrm{MB}, \mathrm{MO}$ and $\mathrm{Pb}(\mathrm{II})$, respectively, using $\mathrm{G} \mathrm{ZnO} \mathrm{NPs,} \mathrm{and} 62.97 \%, 15.06 \%$, and $77.46 \%$ for the $\mathrm{MB}, \mathrm{MO}$ and $\mathrm{Pb}(\mathrm{II})$, respectively, using $\mathrm{T} \mathrm{ZnO}$ NPs. This may be attributed to the small particles size and high surface area of the $\mathrm{Zn}$ O NPs via the green method and assisted by the microwave. Therefore, the further experiments were conducted using the MWG ZnO NPs.

The prepared MWG $\mathrm{ZnO}$ NPs were then applied for $\mathrm{MB}$, MO and $\mathrm{Pb}(\mathrm{II})$ removal at different experimental conditions: MWG ZnO NPs mass, contact time, $\mathrm{pH}$, temperature, and ionic strength of the solution. The impact of MWG ZnO NPs mass on the removal of $\mathrm{MB}, \mathrm{MO}$ and $\mathrm{Pb}(\mathrm{II})$ was optimized in model solution, and the results are presented in Fig. 6. It is obvious that a slight enhancement in the removal percentage of $\mathrm{MO}$, and $\mathrm{MB}$ with increasing MWG ZnO NPs mass, and in contrary, significant enhancement in the removal percentage of $\mathrm{Pb}(\mathrm{II})$ was observed. Increasing the MWG ZnO NPs mass from $2 \mathrm{mg}$ to 15 mg associated with percentage removal from $68.8 \%$ to $78.0 \%, 32.0 \%$ to 38.4 , and 47.32 to $90.7 \%$, for the $\mathrm{MB}, \mathrm{MO}$ and $\mathrm{Pb}(\mathrm{II})$, respectively. This may be attributed to the increase of the active binding sites at MWG ZnO NPs available to bind MB, MO and $\mathrm{Pb}(\mathrm{II})$. Further increase in the MWG ZnO NPs mass to 20 and up to $30 \mathrm{mg}$ had a negligible impact on the 
removal process. Hence, the coming experiments were performed by applying $15 \mathrm{mg}$ of MWG ZnO NPs.

Contact time between adsorbate and the solid adsorbent in the solution is one of the key factors and present an advantage for choosing the suitable adsorbent. Therefore, this part studied the interaction time impact on $\mathrm{MB}, \mathrm{MO}$ and $\mathrm{Pb}(\mathrm{II})$ removal by MWG ZnO NPs from solution. As it shown in Fig. 7, MO removal percentage was found to enhanced sharply within the first 10 minutes, with a percent removal of $72.84 \%$, and reached equilibrium with $75.32 \%$ removal after 15 minutes, whereas in the case of $\mathrm{MB}$, removal percentage increased gradually and equilibrium was achieved within 30.0 minutes with removal percentage of $34.17 \%$. On the other hand, $\mathrm{Pb}(\mathrm{II})$ removal percentage increase sharply within the first 30.0 minutes and equilibrium was achieved with $87.02 \%$. In this respect, the interaction time 30.0 minutes for $\mathrm{MB}, \mathrm{MO}$ and $\mathrm{Pb}(\mathrm{II})$ removal by $\mathrm{MWG} \mathrm{ZnO}$ NPs was implemented for the following experiments to confirm equilibration.

Solution $\mathrm{pH}$ significantly influences the removal/adsorption process, particularly for organic dyes such as $\mathrm{MO}$, and $\mathrm{MB}$, as well as $\mathrm{Pb}(\mathrm{II})$, in addition to the surface charge of the solid adsorbent MWG ZnO NPs. The point of zero charge (Pzc) of $\mathrm{ZnO}$ is normally between $\sim 8.7-9.7$, indicating that at $\mathrm{pH}$ values less than 8.7 , the surface charges of MWG $\mathrm{ZnO}$ NPs is positive, and at $\mathrm{pH}$ values more than 8.7, the surface charges of MWG $\mathrm{ZnO}$ NPs is negative. Also, the $\mathrm{pKa}$ value of $\mathrm{MO}$ is 3.47, indicating that at $\mathrm{pH}$ values below 3.47, MO molecules are neutral, and for $\mathrm{pH}$ values above 3.47 , the anionic species are the predominant. On the other hand, the $\mathrm{pKa}$ value of $\mathrm{MB}$ is 3.80 , indicating that at $\mathrm{pH}$ values below 3.47, MB molecules are neutral, and for $\mathrm{pH}$ values above 3.80, the cationic species are the predominant. Meanwhile, in the case of $\mathrm{Pb}(\mathrm{II})$ at $\mathrm{pH}$ values less than $7.00,[\mathrm{~Pb}(\mathrm{II})]$ exits pronominally as soluble $\mathrm{Pb}(\mathrm{II})$, and at $\mathrm{pH}$ above 7.0 and $[\mathrm{Pb}(\mathrm{II})]$ usually precipitate in the form of $\mathrm{Pb}(\mathrm{OH})_{2}$. Accordingly, the effect of solution $\mathrm{pH}$ on $\mathrm{MB}, \mathrm{MO}$ and $\mathrm{Pb}(\mathrm{II})$ removal was studied in the $\mathrm{pH}$ values 2.00 to 10.0 and the results were presented in Fig. 
8. The removal of $\mathrm{MO}$ was enhanced gradually by rising the $\mathrm{pH}$ from $2.00(11.2 \%$ removal) and the maximum removal was observed at $\mathrm{pH} 5.0$ (64.7\% removal), whereas the removal of $\mathrm{MB}$ was increased slightly by rising the solution $\mathrm{pH}$ from $2.00(27.0 \%$ removal) and the maximum removal was observed at $\mathrm{pH} 4.00$ (38.2\% removal), meanwhile, the removal of $\mathrm{Pb}(\mathrm{II})$ was enhanced significantly by rising the $\mathrm{pH}$ from 2.0 (3.09\% removal) and the maximum removal was observed at $\mathrm{pH} 5.0$ (87.0\% removal). These results could be explained in the terms of the degree of ionization of both MO and $\mathrm{MB}$, as well as the speciation of the $\mathrm{Pb}(\mathrm{II})$, as the MWG ZnO NPs surface charge is positive. In general, at $\mathrm{pH}$ of 2.0 to 4.0 , the hydronium ions $\left(\mathrm{H}_{3} \mathrm{O}^{+}\right)$concentration is very high compared with $\mathrm{MB}, \mathrm{MO}$ and $\mathrm{Pb}(\mathrm{II})$, and out-compete with $\mathrm{MB}, \mathrm{MO}$ and $\mathrm{Pb}$ (II) for the active binding sites at the MWG ZnO NPs surface, which cause low removal of MB, $\mathrm{MO}$ and $\mathrm{Pb}(\mathrm{II})$. At higher $\mathrm{pH}$ values, the \% removal significantly enhanced for $\mathrm{MB}, \mathrm{MO}$ and $\mathrm{Pb}(\mathrm{II})$, and reached the highest removal $\%$ at $\mathrm{pH}$ values of 5.0, 4.0, and 5.0 for $\mathrm{MO}$ (64.7\%), $\mathrm{MB}(38.2 \%)$, and $\mathrm{Pb}(\mathrm{II})(87.0 \%)$, respectively. This is may be sue to the electrostatic attraction between the MWG ZnO NPs surface and the anionic MO molecule, the cationic MB molecule, and the positively charged $\mathrm{Pb}(\mathrm{II})$. At higher $\mathrm{pH}$ values than 5.0, a dramatic decrease in the removal \% was observed for $\mathrm{MO}$, as a results of the electrostatic repulsion forces arises between the MWG ZnO NPs negatively charged surface and the negatively charged anionic MO molecule. On the other hand, for the MB molecules and $\mathrm{Pb}(\mathrm{II})$, the removal was significantly reduced due to the competition with the hydroxyl ions with the $\mathrm{MB}$ molecules, and the precipitation of the $\mathrm{Pb}(\mathrm{II})$ in the form of $\mathrm{Pb}(\mathrm{OH})_{2}$. Accordingly, the $\mathrm{pH}$ of the solution was adjusted at 5.6 was implemented for the following experiments for the $\mathrm{MB}, \mathrm{MO}$ and $\mathrm{Pb}(\mathrm{II})$ removal by MWG ZnO NPs.

For the confirmation of the electrostatic interaction mechanism for the adsorption/removal of $\mathrm{MB}, \mathrm{MO}$ and $\mathrm{Pb}(\mathrm{II})$ removal by $\mathrm{MWG} \mathrm{ZnO}$ NPs, the removal experiment was explored at various ionic strength values by varying the $\left[\mathrm{KNO}_{3}\right]$ from 0.0 to $0.15 \mathrm{M}$ in the studied 
solution. Fig. 9 shows that the removal percentage of $\mathrm{MB}, \mathrm{MO}$ and $\mathrm{Pb}(\mathrm{II})$ decreased significantly with increasing the solution ionic strength by increasing the $\mathrm{KNO}_{3}$ concentration on the solution, from $78.03 \%$ to $8.25 \%, 38.4$ to $11.7 \%$, and $90.7 \%$ to $60.3 \%$, for $\mathrm{MB}, \mathrm{MO}$ and $\mathrm{Pb}(\mathrm{II})$, respectively. This could be due to the formation double layer arises from the positive $\left(\mathrm{K}^{+}\right)$and negative ions $\left(\mathrm{NO}_{3}{ }^{-}\right)$of $\mathrm{KNO}_{3}$ sourrounded the MWG $\mathrm{ZnO}$ NPs leads to the electrostatic repulsion between $\mathrm{MB}, \mathrm{MO}$ and $\mathrm{Pb}(\mathrm{II})$, and $\mathrm{MWG} \mathrm{ZnO}$ NPs. This finding validate the electrostatic interaction mechanism for the $\mathrm{MB}, \mathrm{MO}$ and $\mathrm{Pb}(\mathrm{II})$ removal by MWG ZnO NPs.

The influence of the solution temperature on the removal of $\mathrm{MB}, \mathrm{MO}$ and $\mathrm{Pb}(\mathrm{II})$ removal by MWG ZnO NPs was explored at different temperature; $298 \mathrm{~K}, 303 \mathrm{~K}, 308 \mathrm{~K}, 313 \mathrm{~K}$, $323 \mathrm{~K}$, and $328 \mathrm{~K}$. As shown in Fig. 10, the \% removal of MB, MO and $\mathrm{Pb}(\mathrm{II})$ was greatly influenced by the rising the temperature of the solution, i.e. the rise in the temperature of the solution from 298 to $328 \mathrm{~K}$ accompanied with a slow decrease in the MB, MO and $\mathrm{Pb}$ (II) removal from 38.4 to $14.0 \%, 78.03 \%$ to $43.3 \%$, and $90.0 \%$ to $32.8 \%$, respectively, showing the removal process exothermic-nature. This is may be attributed to enhanced solubility of the $\mathrm{MB}, \mathrm{MO}$ and $\mathrm{Pb}(\mathrm{II})$ in solution, as a results of increasing the average kinetic energies of the molecules by rising the solution temperature. This enhancement in kinetic energy allows the water molecules to overcome their hydrogen bonds and break apart the $\mathrm{MB}, \mathrm{MO}$ and $\mathrm{Pb}(\mathrm{II})$ that are held together by intermolecular attractions, which enhanced their solubility's, and decreased their preference to transfer from the solution to the MWG ZnO NPs solid surface.

The effect of varying both $\mathrm{MO}$, and $\mathrm{MB}$ dyes concentration on the removal of $\mathrm{Pb}(\mathrm{II})$ as well as the varying $\mathrm{Pb}(\mathrm{II})$ on the both $\mathrm{MO}$, and $\mathrm{MB}$ dyes removal by the MWG ZnO NPs was studied and the results were presented in Fig. 11 and Fig. 12. The results showed that increasing $\mathrm{MO}$, and $\mathrm{MB}$ dyes concentrations did not affect significantly the removal of $\mathrm{Pb}$ (II) by the MWG $\mathrm{ZnO}$ NPs, as the \% removal of $\mathrm{Pb}$ (II) slightly decreased from $92.1 \%$ 
to $87.7 \%$, by increasing the concentration of both $\mathrm{MO}$, and $\mathrm{MB}$ from $3.0 \mathrm{mg} / \mathrm{L}$ to $8.0 \mathrm{mg} / \mathrm{L}$, respectively. In contrary, increasing the concentration of $\mathrm{Pb}(\mathrm{II})$ in solution from $100 \mathrm{mg} / \mathrm{L}$ to $1500 \mathrm{mg} / \mathrm{L}$ accompanied by a slight enhancement of the MO, and $\mathrm{MB}$ removal, $62.4 \%$ to $74.7 \%$ for $\mathrm{MO}$, and $30.0 \%$ to $31.3 \%$ for $\mathrm{MB}$, respectively, indicating that the presence of $\mathrm{Pb}$ (II) facilitate the adsorption of the $\mathrm{MO}$, and $\mathrm{MB}$ on the MWG ZnO NPs surface, due to the electrostatic interaction.

It was observed that the removal by the MWG ZnO Nps was as the following order; $\mathrm{Pb}(\mathrm{II})$ $>\mathrm{MO}>>\mathrm{MB}$. The outstanding $\mathrm{Pb}(\mathrm{II})$ removal may be attributed to the small radius of the $\mathrm{Pb}(\mathrm{II}) ; 0.12 \mathrm{~nm}$, compared with the MO, and MB dyes. Moreover, MO dye had higher removal compared with the $\mathrm{MB}$ dye due to the fact that at the optimal $\mathrm{pH}$ value of 5.6, the MO dye presents as anionic molecule; negatively charged, whereas the MB dye presents as a cationic molecule; positively charged, while MWG ZnO NPs surface is positively charges. Accordingly, MO had higher removal due to the electrostatic attraction with the positive $\mathrm{ZnO}$ NPs surface, whereas MB had lower removal due to the electrostatic repulsion with the positive $\mathrm{ZnO}$ NPs surface.

\subsection{Kinetics and thermodynamics studies}

This section focus on the emphasizing $\mathrm{MB}, \mathrm{MO}$ and $\mathrm{Pb}(\mathrm{II})$ removal by MWG ZnO NPs through different mathematical kinetic models usually used for the description of the interaction between $\mathrm{MB}, \mathrm{MO}$ and $\mathrm{Pb}(\mathrm{II})$ and $\mathrm{MWG} \mathrm{ZnO}$ NPs for better environmental application. Accordingly, the Lagergren pseudo-first-order kinetic model (PFO) [31] and the pseudo-second-order kinetic model (PSO) [32], were applied to the experimental removal data for $\mathrm{MB}, \mathrm{MO}$ and $\mathrm{Pb}(\mathrm{II})$ from solution by solid MWG $\mathrm{ZnO}$ NPs presented in

Fig. 14. The linearized form of the PFO is presented in Equation (3):

$$
\ln \left(q_{\mathrm{e}}-q_{t}\right)=\ln q_{\mathrm{e}}-k_{\mathrm{1}} t
$$


where $k_{1}\left(\mathrm{~min}^{-1}\right)$ is the PFO rate coefficient, and $q_{\mathrm{e}}$ and $q_{t}$ represent the amount of MB, $\mathrm{MO}$ and $\mathrm{Pb}(\mathrm{II})$ removed/unit mass of $\mathrm{MWG} \mathrm{ZnO}$ NPs at equilibrium and at any time $t$, respectively. The application of the PFO to the removal data at Fig. $\mathbf{1 3}$ and by plotting $\ln \left(q_{\mathrm{e}}-q_{t}\right)$ versus $t$, straight lines does not obtained for $\mathrm{MB}, \mathrm{MO}$ and $\mathrm{Pb}(\mathrm{II})$, and convergence values $\left(R^{2}\right)$ of 0.726, 0.892, and 0.940, respectively, as presented in Fig. 14 and Table 1, showing the unsuitability of the PFO kinetic model for the description of the $\mathrm{MB}, \mathrm{MO}$ and $\mathrm{Pb}(\mathrm{II})$ removal by MWG ZnO NPs.

The linearized equation of PSO is:

$\frac{t}{q_{t}}=\frac{1}{k_{2} q_{\mathrm{e}}^{2}}+\frac{t}{q_{\mathrm{e}}}$

where $k_{2}(\mathrm{~g} /(\mathrm{mg} \min ))$ is the PSO rate coefficient. Applying Equation (4) to the removal data at Fig. 13 and by plotting $t / q_{t}$ versus $t$, straight lines and appropriate convergence were obtained for $\mathrm{MB}, \mathrm{MO}$ and $\mathrm{Pb}(\mathrm{II})$ with an $R^{2}$ values higher than 0.980 , as shown in Table 1 and Fig. 15, showing the relevancy of PSO kinetic model for descripting the removal by MWG ZnO NPs from aqueous solution.

The appropriateness of the PSO kinetic model in comparison to the Lagergren PFO kinetic model was validated using two statistical tests, the chi-square test [33]; Equation (5), and the and sum of the squares of errors (SSE) [34]; Equation (6).

$$
\begin{gathered}
\chi^{2}=\sum \frac{\left(q_{\mathrm{e}, \mathrm{calc}}-q_{\mathrm{e}, \mathrm{exp}}\right)^{2}}{q_{\mathrm{e}, \mathrm{calc}}}, \\
\mathrm{SSE}=\sum_{i=1}^{n}\left(q_{\mathrm{e}, \mathrm{calc}}^{i}-q_{\mathrm{e}, \mathrm{exp}}^{i}\right)^{2},
\end{gathered}
$$

where $q_{\mathrm{e}, \text { calc }}$ and $q_{\mathrm{e} \text {,exp }}$ are the calculated and experimental amounts removed of MB, MO and $\mathrm{Pb}(\mathrm{II})$ per unit mass of MWG ZnO NPs at equilibrium. For MO removal, the $\chi^{2}$ values obtained were 31.9 and 0.00 , and the SSE values were 20.8 and 0.00 for the PFO and the PSO, respectively, whereas for MB removal, the $\chi^{2}$ values were 2.65 and 0.00 , and the 
SSE values were 2.57 and 0.00 for the PFO and the PSO, respectively, and for $\mathrm{Pb}$ (II) removal, the $\chi^{2}$ values were 31.1 and 2.76, and the SSE values were 14747 and 1761.9 for the PFO and the PSO, respectively. These results indicated the appropriateness of the PSO kinetic model compared with PFO kinetic model for describing the removal of MB, MO and $\mathrm{Pb}(\mathrm{II})$ by MWG ZnO NPs from model solution. Accordingly, it could concluded here that $\mathrm{MB}, \mathrm{MO}$ and $\mathrm{Pb}(\mathrm{II})$ removal by $\mathrm{MWG} \mathrm{ZnO}$ NPs from solution were well characterized by the PSO compared to PFO.

The adsorption usually occurs in four distinctive steps; bulk diffusion, mass action, liquid film diffusion and finally intra-particle diffusion which is classified as a pore and surface diffusion. This part focus on the determination of the rate determining step for the adsorption/diffusion process.

The linearized form of the liquid film diffusion equation is as follows [35]:

$$
\ln (1-F)=-k_{f d} t
$$

where $\mathrm{F}$ is the fractional attainment of equilibrium and equals $\mathrm{q}_{t} / \mathrm{q}_{\mathrm{e}}$ and $k_{f d}\left(\mathrm{~min}^{-1}\right)$ is the film diffusion rate coefficient. By applying Equation (7) to the removal data at Fig. 13 and by plotting $\ln (1-\mathrm{F})$ versus $t$, a straight line was obtained with zero intercept for the $\mathrm{Pb}(\mathrm{II})$ removal by MWG ZnO NPs with acceptable $R^{2}$ value $(0.938)$. On the other hand, for the MO and MB removal, a straight line with zero intercept were obtained within the first 5.0 minutes of adsorption low $R^{2}$ values, 0.833, and 0.860, respectively, as shown in Fig. 16, and Table 1.

The linearized intra particle diffusion equation is presented in Equation [35]:

$$
q_{t}=k_{i d} t^{0.5}+C_{i}
$$

where $k_{i d}\left(\mathrm{mg} /\left(\mathrm{g} \cdot \mathrm{min}^{0.5}\right)\right)$ is the intra particle diffusion coefficient and $C_{\mathrm{i}}(\mathrm{mg} / \mathrm{g})$ is related to the boundary layer thickness. By applying Equation (8) to the removal data at Fig. 13 
and by plotting $\mathrm{q}_{\mathrm{t}}$ versus $t$, a straight line was obtained for the removal of $\mathrm{Pb}$ (II) by MWG ZnO NPs after 30.0 minutes $\left(R^{2}=0.956\right)$, as shown in Fig. 17 and Table 1. On the other hand, for the MO removal, a straight line was obtained after 15.0 minutes $\left(R^{2}=0.941\right)$, and for MB the adsorption data a straight line was obtained after 20.0 minutes $\left(R^{2}=0.840\right)$, as shown in Fig. 17 and Table 1. This may indicated that the MB, MO and $\mathrm{Pb}(\mathrm{II})$ removal was controlled by both liquid film and intra particle diffusion kinetics during the time of adsorption.

The use of MWG ZnO NPs for the $\mathrm{MB}, \mathrm{MO}$ and $\mathrm{Pb}(\mathrm{II})$ removal from real water sample was investigated using sea water and tap water. The concentrations of $\mathrm{MB}, \mathrm{MO}$ and $\mathrm{Pb}(\mathrm{II})$ were measured after the samples collection, and were almost nil. Accordingly, the real water samples were spiked with concentrated solutions of $\mathrm{MB}, \mathrm{MO}$ and $\mathrm{Pb}$ (II) to achieve final concentrations of $5.0 \mathrm{mg} / \mathrm{L}$ for both $\mathrm{MO}$ and $\mathrm{MB}$, and $500 \mathrm{mg} / \mathrm{L}$ for the $\mathrm{Pb}(\mathrm{II})$ to simulate a pollution scenario and to explore the possible application of MWG ZnO NPs as a potential solid material for the remediation of water pollution. MWG ZnO NPs was mixed with the spiked real samples, and the removal percentages of MO were $40.69 \%$, and $76.98 \%$, the removal percentages of $\mathrm{MB}$ were $40.65 \%$, and $36.88 \%$, and for $\mathrm{Pb}(\mathrm{II})$ were $84.22 \%$, and $90.78 \%$ for the sea water, and tap water samples, respectively. These results showed that most of the $\mathrm{Pb}(\mathrm{II})$ were removed from four of the real environmental water samples using the MWG ZnO NPs.

The regeneration and reusability of MWG ZnO NPs for the removal of $\mathrm{MB}, \mathrm{MO}$ and $\mathrm{Pb}(\mathrm{II})$ from solution was explored using methanol, and $0.005 \mathrm{M} \mathrm{HNO}_{3}$ as the desorption media, and washing with deionized water as well as ethanol then deionized water. As it is presented in Fig. 18, which showed that MWG ZnO NPs could be used for five consecutive times for the efficient removal of $\mathrm{MB}, \mathrm{MO}$ and $\mathrm{Pb}(\mathrm{II})$ from solution, with $\mathrm{MO}$ removal of $78.03 \%, 76.98 \%, 72.41 \%, 71.99 \%$, and $71.10 \%$, and MB removal percentages 
of $38.44 \%, 36.88 \%, 35.68 \%, 35.68 \%$, and $35.41 \%$, whereas for $\mathrm{Pb}(\mathrm{II})$ removal percentages of $90.78 \%, 90.18 \%, 86.71 \%, 72.99 \%$, and $70.95 \%$ for each respective cycle. This result indicated the applicability of the solid MWG ZnO NPs as a promising and potential adsorbent for the remediation of polluted environment.

The change of Gibbs free energy $(\Delta G)$, enthalpy $(\Delta H)$, and entropy $(\Delta S)$ are very crucial to understand the thermodynamic feasibility and spontaneity of any chemical or physical process including the environmental remediation. Accordingly, Equations 9-11 were applied to estimate the $\Delta G, \Delta H$, and $\Delta S[36]$ :

$$
\begin{array}{r}
D=\frac{q_{\mathrm{e}}}{C_{\mathrm{e}}}, \\
\ln D=\frac{\Delta S}{R}-\frac{\Delta H}{R T}, \\
\Delta G=\Delta H-T \Delta S,
\end{array}
$$

as $D$ is the thermodynamics distribution coefficients calculated with the amount removed at equilibrium of $\mathrm{MB}, \mathrm{MO}$ and $\mathrm{Pb}(\mathrm{II})$ per unit mass of MWG $\mathrm{ZnO}$ NPs (milligrams pollutant/gram of MWG ZnO NPs) and $C_{\mathrm{e}}$ is the equilibrium concentration of $\mathrm{MB}, \mathrm{MO}$ and $\mathrm{Pb}(\mathrm{II})$ in solution (mg/L). As presented in Fig. 19, by plotting $\ln D$ versus $1 / T$, straight lines with acceptable regression coefficients $\left(\mathrm{R}^{2}\right)$ values were obtained for $\mathrm{MB}, \mathrm{MO}$ and $\mathrm{Pb}$ (II) and the intercept and slope were used to estimate $\Delta S$ and $\Delta H$, respectively. The $\Delta S$, $\Delta H$, and $\Delta G$ values, for MO removed/adsorbed by MWG ZnO NPs were calculated and were $-116.4 \mathrm{~J} / \mathrm{mol} \mathrm{K},-38.8 \mathrm{~kJ} / \mathrm{mol}$, and $-4.13 \mathrm{~kJ} / \mathrm{mol}$, respectively, whereas for the removal of $\mathrm{MB}$, the thermodynamic parameters; $\Delta S, \Delta H$, and $\Delta G$, values were -121.5 $\mathrm{J} / \mathrm{mol} \mathrm{K},-35.6 \mathrm{~kJ} / \mathrm{mol}$, and $+0.616 \mathrm{~kJ} / \mathrm{mol}$, respectively. Meanwhile, whereas for the removal of $\mathrm{Pb}(\mathrm{II})$, the thermodynamic parameters; $\Delta S, \Delta H$, and $\Delta G$, values were -248.7 $\mathrm{J} / \mathrm{mol} \mathrm{K},-80.3 \mathrm{~kJ} / \mathrm{mol}$, and $-6.18 \mathrm{~kJ} / \mathrm{mol}$, respectively. For $\mathrm{MB}, \mathrm{MO}$ and $\mathrm{Pb}(\mathrm{II})$ removal, 
the negative change values, demonstrating a decline in the freedom degrees at the liquidsolid interface due to the adsorption and immobilization of $\mathrm{MB}, \mathrm{MO}$ and $\mathrm{Pb}(\mathrm{II})$ on the solid MWG ZnO NPs surface. Also, the enthalpy changes for the $\mathrm{MB}, \mathrm{MO}$ and $\mathrm{Pb}$ (II) removal were negative, demonstrating that the removal was exothermic in nature, and greatly supports the process spontaneity. Also, the $\Delta G$ values were $\mathrm{Pb}(\mathrm{II}) \gg>\mathrm{MO} \gg \mathrm{MB}$, indicating the preferential adsorption and binding of $\mathrm{Pb}$ (II) followed by $\mathrm{MO}$, and then $\mathrm{MB}$ to solid MWG ZnO NPs surface. Appropriately, the negative values of the thermodynamic parameters $\Delta G, \Delta H$, and $\Delta S$ indicated that the removal of $\mathrm{MB}, \mathrm{MO}$ and $\mathrm{Pb}$ (II) by the solid MWG ZnO NPs from solution is an driven by the $\Delta H$. The negative entropy values, demonstrating a reduction in the freedom degrees at the liquid solid interface because of the adsorption/binding of $\mathrm{MB}, \mathrm{MO}$ and $\mathrm{Pb}(\mathrm{II})$ of to the solid MWG ZnO NPs, against the removal process spontaneity. Also, the negative $\Delta H$ values showed that the process was exothermic in nature and greatly supports the removal process spontaneity and opposing to the negative $\Delta S$ values. Furthermore, it is well know that the adsorption enthalpy value could be used to differentiate between the nature of the adsorption either physical or chemical, low adsorption enthalpy $(5-40 \mathrm{~kJ} / \mathrm{mol})$ is one of the main characteristics of physical adsorption, whereas high adsorption enthalpy $(40-800 \mathrm{~kJ} / \mathrm{mol})$ is one of the main characteristics of chemical adsorption [37]. Therefore, on the basis of the $\Delta H$ values for $\mathrm{MO}$, and $\mathrm{MB}$ adsorption were $-38.8 \mathrm{~kJ} / \mathrm{mol}$, and $-35.6 \mathrm{~kJ} / \mathrm{mol}$ indicating the physical nature of the adsorption, whereas for the $\mathrm{Pb}(\mathrm{II})$ adsorption the $\Delta H$ value was $-80.3 \mathrm{~kJ} / \mathrm{mol}$ indicating the chemical in nature of the adsorption.

\section{Conclusion}

This research work investigated the $\mathrm{ZnO}$ NPs preparation via green and eco-friendly microwave assisted method (GMW ZnO NPs) and their application for the removal of methyl orange (MO), and methylene blue (MB), as well as toxic $\mathrm{Pb}(\mathrm{II})$ from solution. 
GMW ZnO NPs were characterized by different techniques: XRD, SEM, and textural properties. The results demonstrated the efficacious preparation of wurtzite $\mathrm{ZnO}$ nanoparticles with irregular flake-shape composed of very small particles with an average particle size of and $33 \mathrm{~nm}$. The effect of different environmental conditions on the removal of $\mathrm{MB}, \mathrm{MO}$ and $\mathrm{Pb}(\mathrm{II})$ by the GMW ZnO NPs were studied, and the findings showed that most of the studied pollutants were removed using 15.0 mg GMW ZnO NPs within 30 minutes at pH 5.6 and $298 \mathrm{~K}$. The removal process was explored kinetically, and it was found that the pseudo-second-order model is suitable for the description of the removal process with experimental removal capacities of 5.21, 2.57, and 596 mg GMW ZnO NPs per gram of $\mathrm{MB}, \mathrm{MO}$ and $\mathrm{Pb}(\mathrm{II})$, respectively, indicating the great probability of applying GMW ZnO NPs for environmental remediation. The thermodynamics study presented the spontaneity of the removal process, which is associated with the negative enthalpy, and negative entropy values, showing that the removal of $\mathrm{MB}, \mathrm{MO}$ and $\mathrm{Pb}(\mathrm{II})$ by the GMW $\mathrm{ZnO}$ NPs is an enthalpy-driven process. Finally, GMW ZnO NPs were used for removal of $\mathrm{MB}, \mathrm{MO}$ and $\mathrm{Pb}(\mathrm{II})$ from real water samples. The results demonstrated the high efficacy of the GMW ZnO NPs and their possible application for the remediation of polluted environment.

\section{Acknowledgments}

This project was funded by the Deanship of Scientific Research (DSR), King Abdulaziz University, Jeddah, Saudi Arabia under grant no. (KEP-PhD-2-130-40). The authors, therefore, acknowledge with thanks DSR technical and financial support.

\section{References}

[1] A.E. Burakov,, E. V. Galunin,, I. V. Burakova,, A.E. Kucherova,, S. Agarwal,, A.G. Tkachev,, V.K. Gupta, Ecotoxicology and Environmental Safety 148 (2018) 
$702-12$

[2] R.H. Al-Dahiri,, A.M. Turkustani,, M.A. Salam, International Journal of Electrochemical Science 15(1) (2020) 442-57.

[3] A. Sirelkhatim,, S. Mahmud,, A. Seeni,, N.H.M. Kaus,, L.C. Ann,, S.K.M. Bakhori,, H. Hasan,, D. Mohamad, Nano-Micro Letters 7(3) (2015) 219-42.

[4] P.K. Mishra,, H. Mishra,, A. Ekielski,, S. Talegaonkar,, B. Vaidya, Drug Discovery Today 22(12) (2017) 1825-34.

[5] Z.Y. Zhang,, H.M. Xiong, Materials 8(6) (2015) 3101-27. 10.3390/ma8063101.

[6] H.M. Xiong, Advanced Materials 25(37) (2013) 5329-35.

[7] M. Alavi, N. Karimi, I. Salimikia, Journal of Industrial and Engineering Chemistry 72 (2019) 457-473.

[8] J.W. Rasmussen,, E. Martinez,, P. Louka,, D.G. Wingett, Expert Opinion on Drug Delivery 7(9) (2010) 1063-77.

[9] P.J.P. Espitia,, N. de F.F. Soares,, J.S. dos R. Coimbra,, N.J. de Andrade,, R.S. Cruz,, E.A.A. Medeiros, Food and Bioprocess Technology 5(5) (2012) 1447-64.

[10] N. S. Kumar, V. R. M. Reddy, M. Asif, M. Boumaza, K. Mallikarjuna, Journal of the Taiwan Institute of Chemical Engineers 116 (2020) 92-100.

[11] A. Becheri,, M. Dürr,, P. Lo Nostro,, P. Baglioni, Journal of Nanoparticle Research 10(4) (2008) 679-89.

[12] M. Azizi-Lalabadi, A. Ehsani, B. Divband, M. Alizadeh-Sani, Sci Rep 9, 17439 (2019). https://doi.org/10.1038/s41598-019-54025-0

[13] A. Khataee, M. Kıranşan, S. Karaca, M.Sheydaei, Journal of the Taiwan Institute of Chemical Engineers Volume 74 (2017) 196-204.

[14] M. Pirsaheb, B. Shahmoradi, M. Beikmohammadi, E. Azizi, H. Hossini, G. Md Ashraf. Sci Rep 7, 1473 (2017). https://doi.org/10.1038/s41598-017-01461-5.

[15] K.L. Bae,, J. Kim,, C.K. Lim,, K.M. Nam,, H. Song, Nature Communications 8(1) 
(2017) 1-9.

[16] C. Xin,, M. Hu,, K. Wang,, X. Wang, Langmuir 33(27) (2017) 6667-76.

[17] D. Phan, R. A. Rebia, Y. Saito, D. Kharaghani, M. Khatri, T. Tanaka, H.Lee, I Kim, Journal of Industrial and Engineering Chemistry 85 (2020) 258-268.

[18] T. Sheela,, Y.A. Nayaka,, R. Viswanatha,, S. Basavanna,, T.G. Venkatesha, Powder Technology 217 (2012) 163-70.

[19] A. Kolodziejczak-Radzimska,, T. Jesionowski, Materials 7(4) (2014) 2833-81.

[20] H. Agarwal,, S. Venkat Kumar,, S. Rajeshkumar, Resource-Efficient Technologies 3(4) (2017) 406-13.

[21] H. Agarwal,, A. Nakara,, S. Menon,, V.K. Shanmugam, Journal of Drug Delivery Science and Technology 53 (2019) 101212.

[22] G. Sharmila,, M. Thirumarimurugan,, C. Muthukumaran, Microchemical Journal 145 (2019) 578-87.

[23] B.A. Fahimmunisha,, R. Ishwarya,, M.S. AlSalhi,, S. Devanesan,, M. Govindarajan,, B. Vaseeharan, Journal of Drug Delivery Science and Technology 55 (2020) 101465.

[24] A. Mirzaei,, G. Neri, Sensors and Actuators, B: Chemical 237 (2016) 749-75.

[25] A. Kumar,, Y. Kuang,, Z. Liang,, X. Sun, Materials Today Nano 11 (2020) 100076.

[26] N. Garino,, T. Limongi,, B. Dumontel,, M. Canta,, L. Racca,, M. Laurenti,, M. Castellino,, A. Casu,, A. Falqui,, V. Cauda, Nanomaterials 9 (2019) 1-17.

[27] N. Salah,, W.M. AL-Shawafi,, A. Alshahrie,, N. Baghdadi,, Y.M. Soliman,, A. Memic, Materials Science and Engineering C 99 (2019) 1164-73.

[28] D. Papadaki,, S. Foteinis, G.H. Mhlongo,, S.S. Nkosi,, D.E. Motaung, S.S. Ray,, T. Tsoutsos,, G. Kiriakidis, Science of the Total Environment 586 (2017) 566-75.

[29] S. Azizi,, R. Mohamad,, M.M. Shahri,, D.J. McPhee, Molecules 22(2) (2017) 1- 
13.

[30] A. West, Solid state chemistry and its applications, Wiley, New York, 1986.

[31] S. Lagergren, Kungliga Svenska Vetenskapsakademiens Handlingar 24 (1898) 139.

[32] W. Rudzinski,, W. Plazinski, Adsorption 15 (2009) 181-92.

[33] V.B. Bagdonavicius,, M.S. Nikulin, International Journal of Applied Mathematics \& Statistics 24(SI-11A) (2011).

[34] R.R. Karri,, J.N. Sahu,, N.S. Jayakumar, Journal of the Taiwan Institute of Chemical Engineers 80 (2017) 472-487.

[35] G.E. Boyd,, A.W. Adamson,, L.S. Myers, J. Am. Chem. Soc. 69 (1947) 28362848.

[36] M.A. Salam, Colloids and Surfaces A: Physicochemical and Engineering Aspects 419 (2013) 69-79.

[37] P. Atkins,, J. de Paula, Physical Chemistry, 9th ed., W. H. Freeman, 2009. 
Table 1. Parameters of the kinetic models for the removal of $\mathrm{MB}, \mathrm{MO}$ and $\mathrm{Pb}$ (II) from model solution.

\begin{tabular}{|c|c|c|c|c|c|c|c|c|c|}
\hline Paramete & Pseudo-f & t-order & kineti & nodel & Pseudo-se & ond-or & der 1 & kine & ic model \\
\hline & $\mathrm{Pb}(\mathrm{II})$ & $\mathrm{MO}$ & & & $\mathrm{Pb}(\mathrm{II})$ & $\mathrm{MO}$ & & $\mathrm{MB}$ & \\
\hline$k_{1}$ & 0.0796 & 0.034 & & & - & - & & - & \\
\hline$k_{2}$ & - & - & - & & $247 \times 10^{-6}$ & 0.364 & & 0.16 & \\
\hline$q_{\mathrm{e}, \exp }(\mathrm{mg} / \mathrm{g})$ & 595.58 & 5.212 & & & 595.58 & 5.212 & & 2.57 & \\
\hline$q_{\mathrm{e}, \text { calc }}(\mathrm{mg} / \mathrm{g})$ & 474.146 & 0.651 & & & 637.56 & 5.198 & & 2.57 & \\
\hline$R^{2}$ & 0.853 & 0.726 & & & 0.986 & 0.9999 & & 0.99 & \\
\hline$\chi^{2}$ & 31.1 & 31.93 & & & 2.76 & $\begin{array}{l}3.8 \times 1 \\
5\end{array}$ & & 1.25 & $\times 10^{-6}$ \\
\hline$S S E$ & 14746.9 & 20.799 & & & 1761.9 & 0.0002 & & 3.2 & $\times 10^{-6}$ \\
\hline Parameter & Liquid fi & diffusi & & & Intra-Part & & & & \\
\hline & $\mathrm{Pb}(\mathrm{II})$ & & $\mathrm{MO}$ & MB & $\mathrm{Pb}(\mathrm{II})$ & & $\mathrm{MO}$ & & $\mathrm{MB}$ \\
\hline$k_{f d}$ & 0.0796 & & 0.034 & 0.035 & - & & - & & - \\
\hline$R^{2}$ & 0.94 & & 0.73 & 0.89 & & & & & \\
\hline$R^{2}$ & - & & - & - & 0.956 & & 0.94 & & 0.84 \\
\hline
\end{tabular}




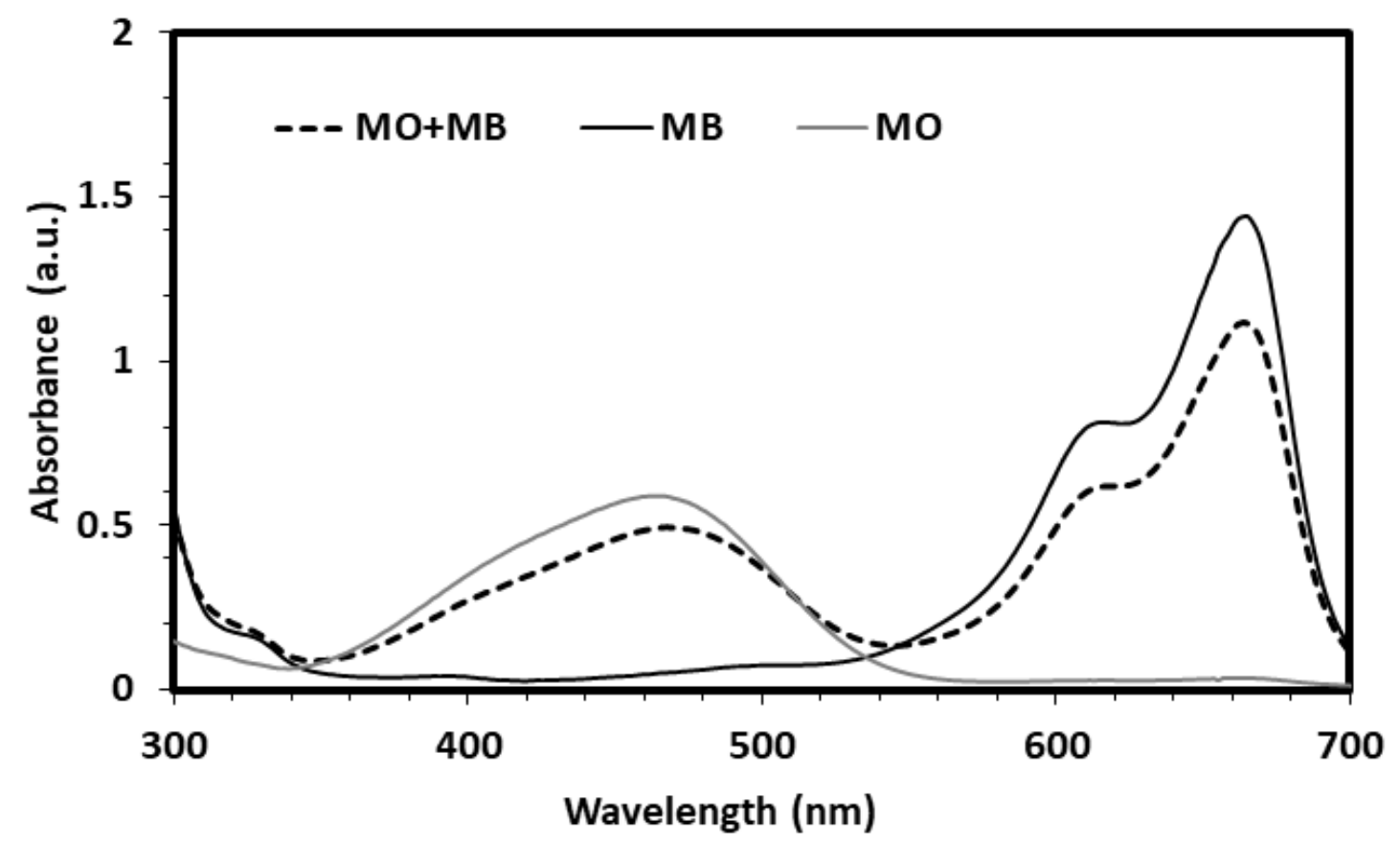

Fig. 1. The Uv-vis spectra of MO, and MB in aqueous solution. 

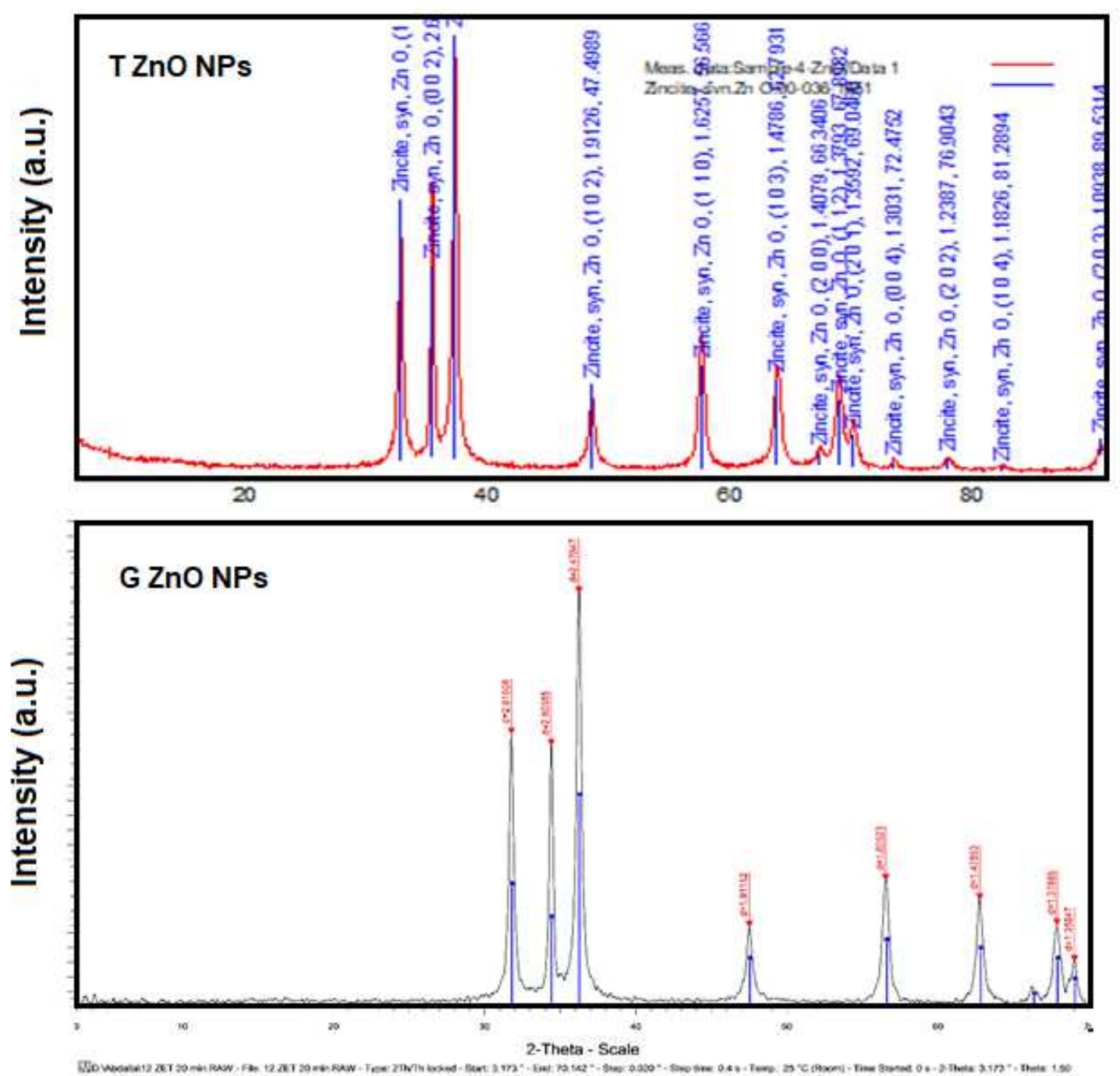

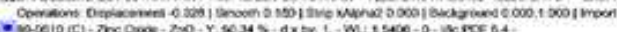

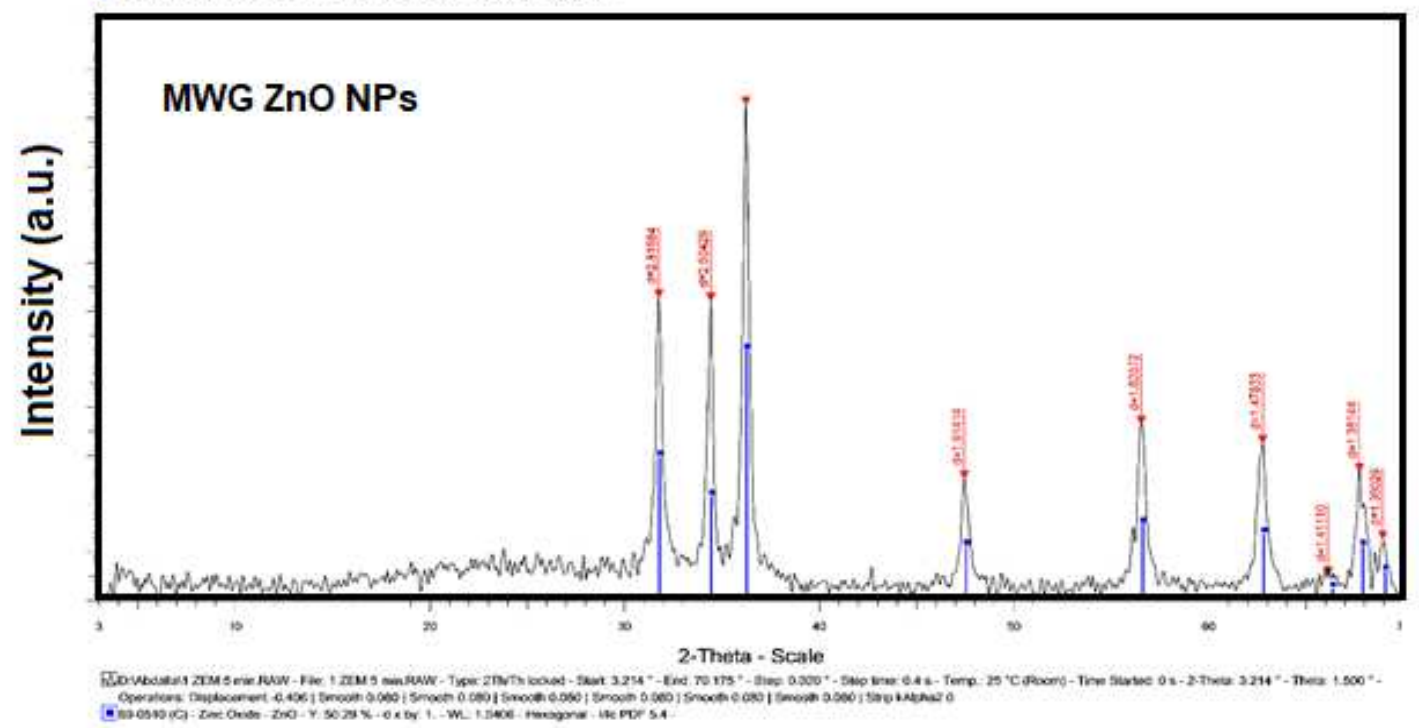

Fig. 2. XRD patterns of different $\mathrm{ZnO}$ NPs. 

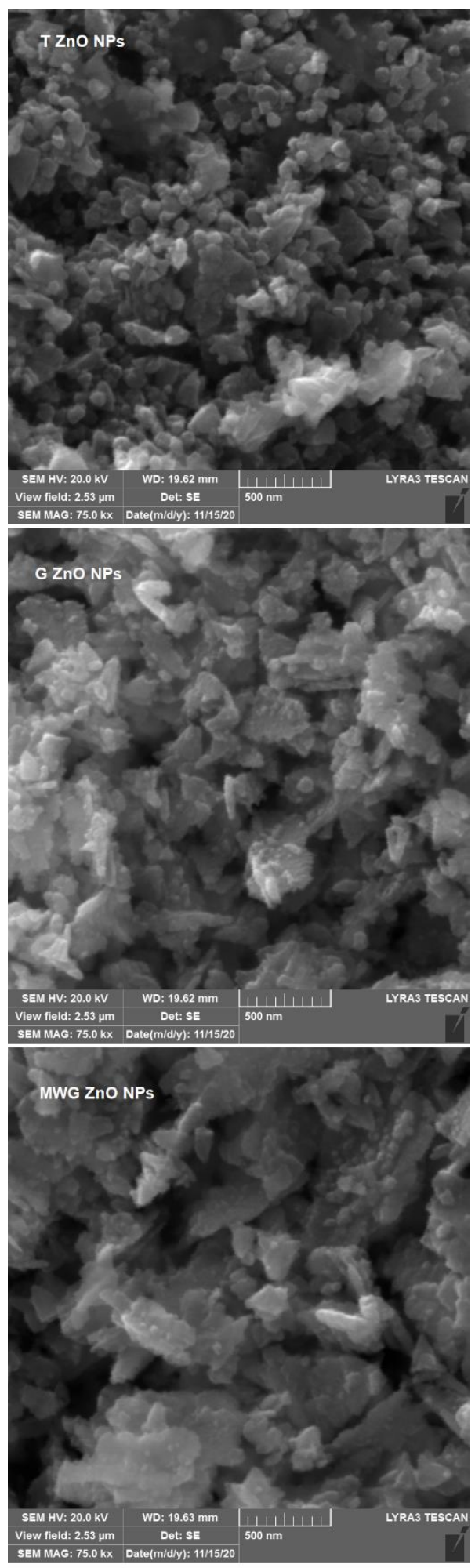

Fig. 3. SEM images of different ZnO NPs. 

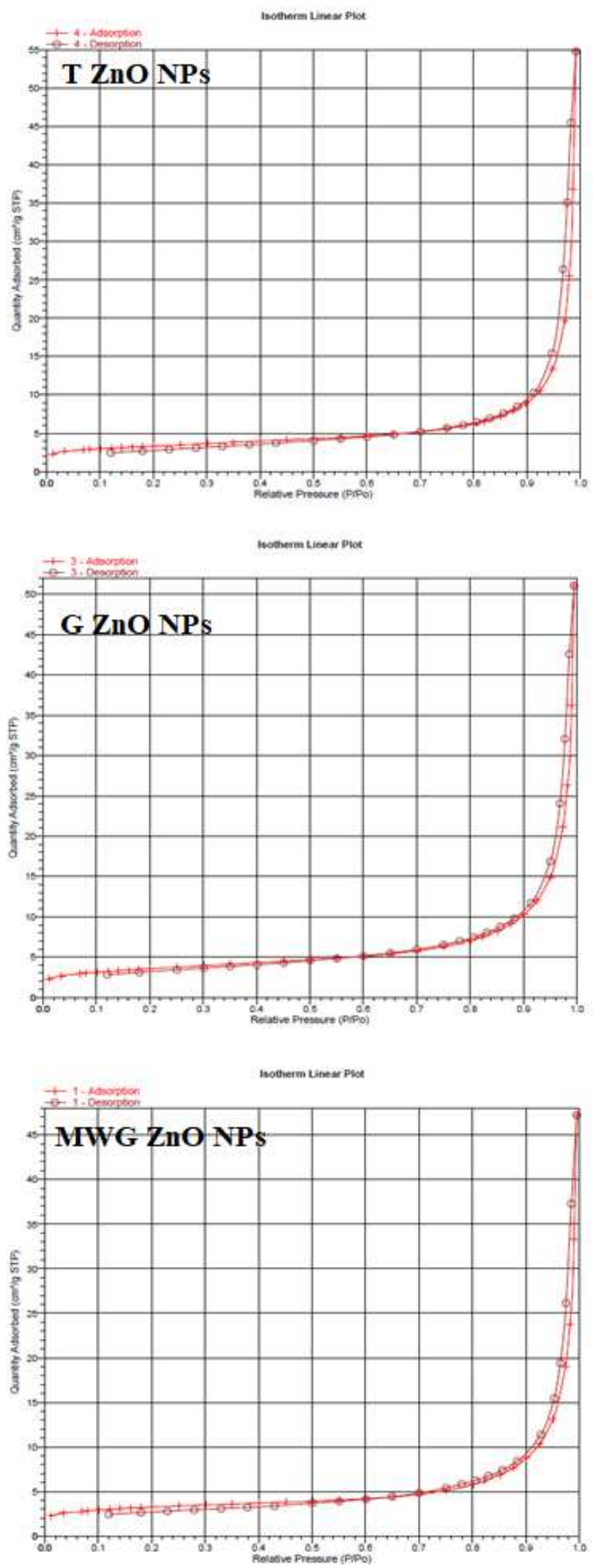

Fig. 4. $\mathrm{N}_{2}$ adsorption/desorption isotherms of different $\mathrm{ZnO}$ NPs. 


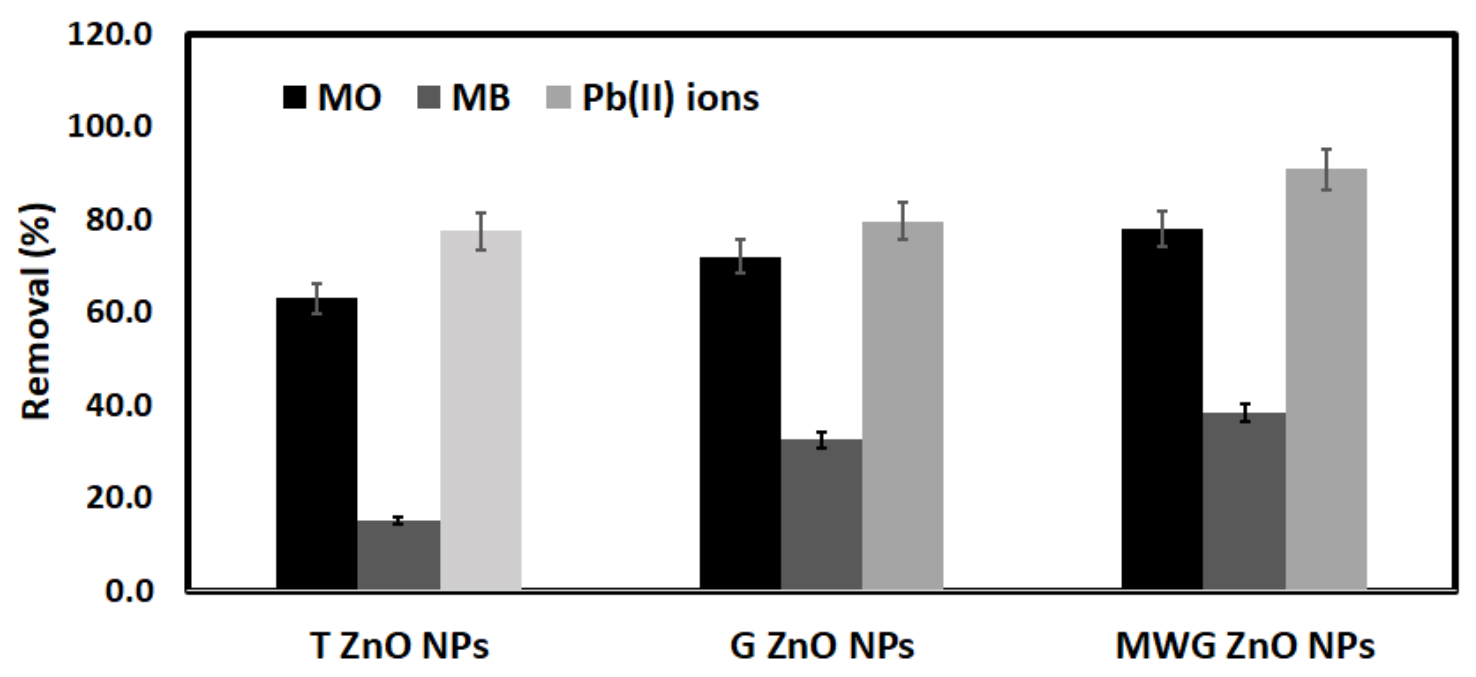

Fig. 5. The removal efficacies of $\mathrm{MB}, \mathrm{MO}$ and $\mathrm{Pb}(\mathrm{II})$ by different $\mathrm{ZnO}$ NPs; $\mathrm{T} \mathrm{ZnO}$ NPs, G ZnO NPs, and MWG ZnO NPs, from model solution. (Experimental conditions: 20.0 $\mathrm{ml}$ solution, mass $15 \mathrm{mg}$, pH 5.6, 30 minutes, $298 \mathrm{~K}$, and [MO] $5.0 \mathrm{mg} / \mathrm{L}$, [MB] $5.0 \mathrm{mg} / \mathrm{L}$, $[\mathrm{Pb}(\mathrm{II})] 500 \mathrm{mg} / \mathrm{L})$. 


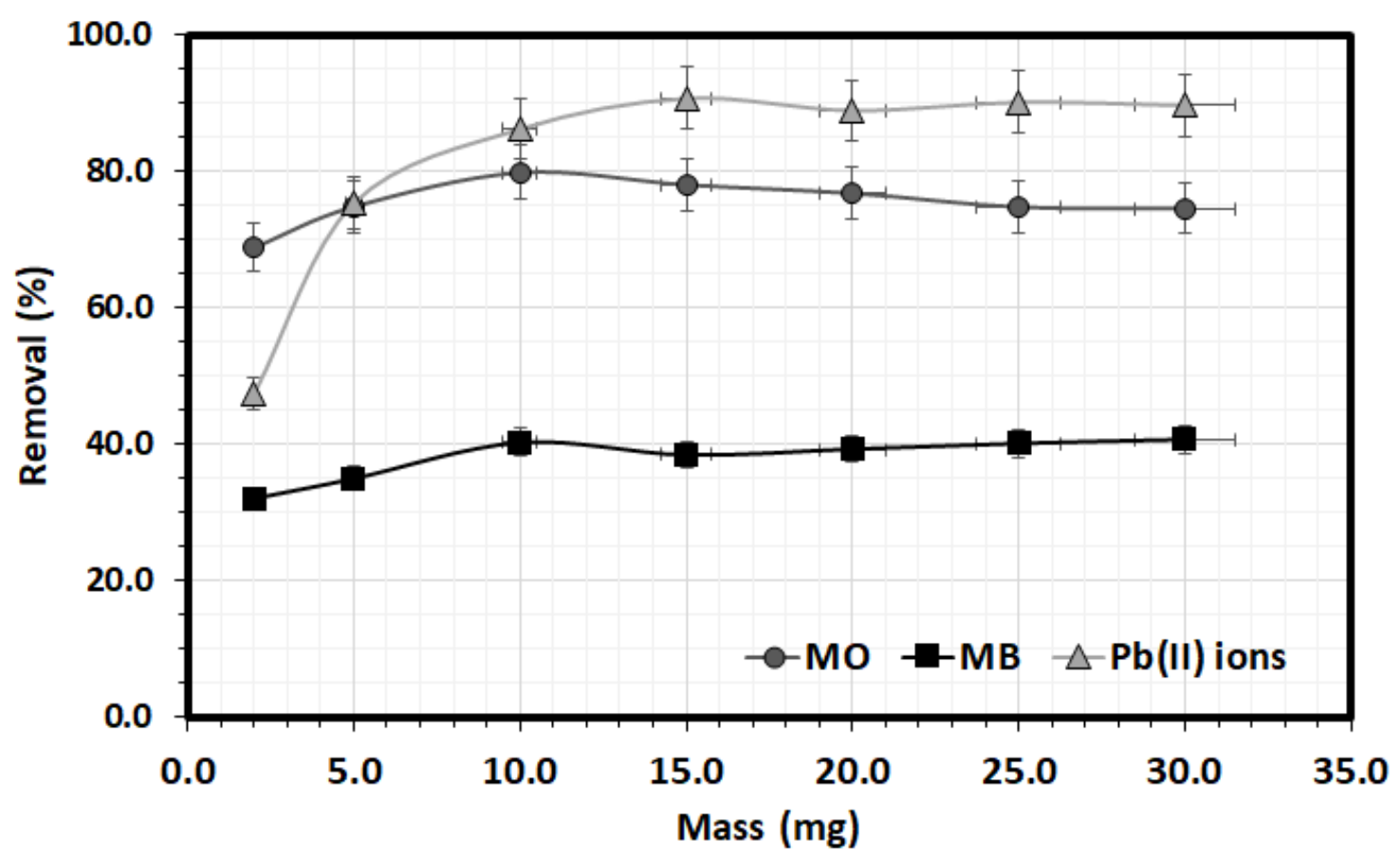

Fig. 6. Effect of the MWG $\mathrm{ZnO}$ NPs mass on the removal of $\mathrm{MB}, \mathrm{MO}$ and $\mathrm{Pb}(\mathrm{II})$ from model solution. (Experimental conditions: $20.0 \mathrm{ml}$ solution, $\mathrm{pH}$ 5.6, 30 minutes, $298 \mathrm{~K}$, and [MO] $5.0 \mathrm{mg} / \mathrm{L},[\mathrm{MB}] 5.0 \mathrm{mg} / \mathrm{L},[\mathrm{Pb}(\mathrm{II})] 500 \mathrm{mg} / \mathrm{L})$. 


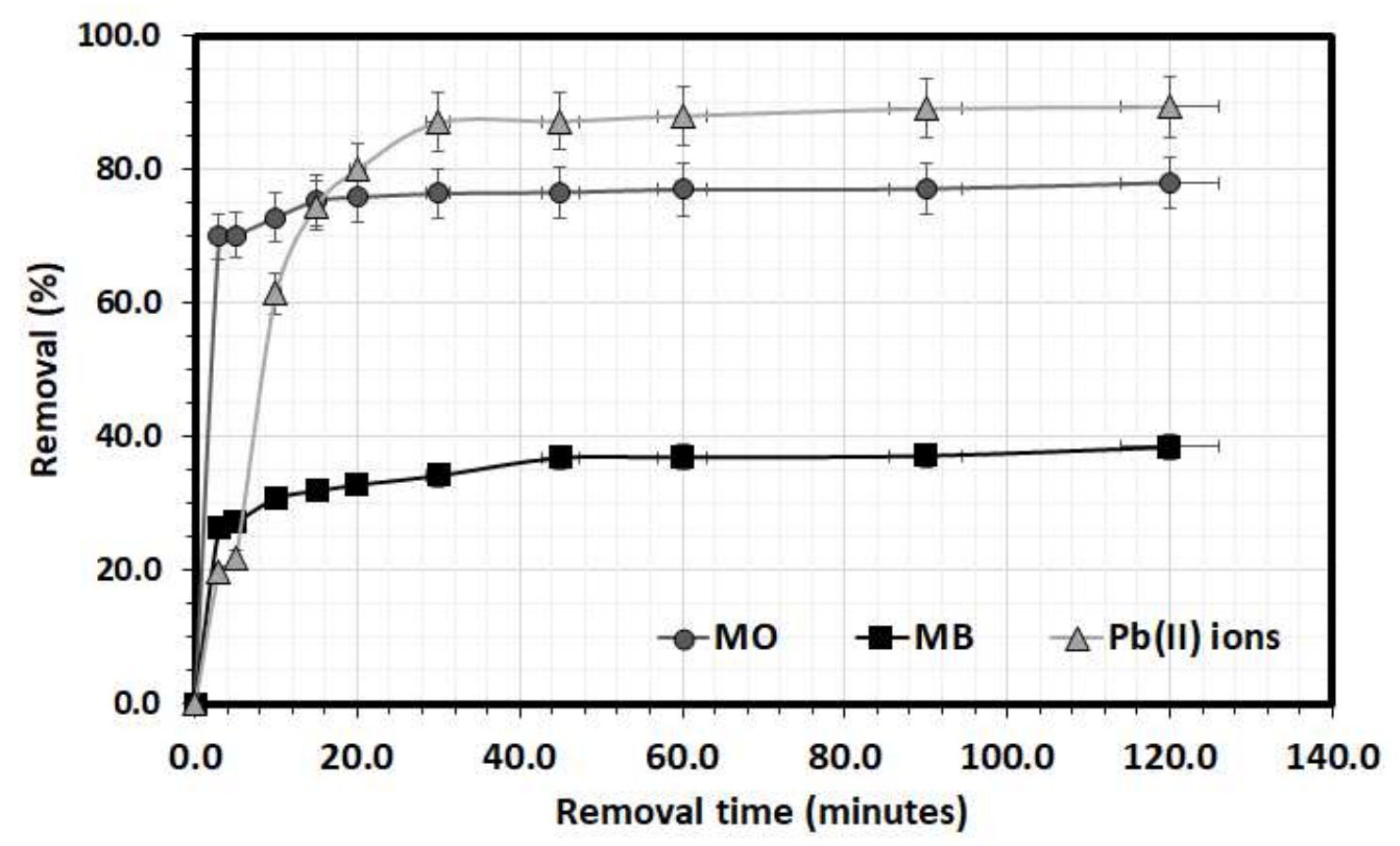

Fig. 7. Effect of the removal time on the removal of $\mathrm{MB}, \mathrm{MO}$ and $\mathrm{Pb}(\mathrm{II})$ from model solution using MWG ZnO NPs. (Experimental conditions: $20.0 \mathrm{ml}$ solution, pH 5.6, MWG ZnO NPs mass $15.0 \mathrm{mg}, 298 \mathrm{~K}$, and [MO] $5.0 \mathrm{mg} / \mathrm{L}$, [MB] $5.0 \mathrm{mg} / \mathrm{L},[\mathrm{Pb}(\mathrm{II})] 500 \mathrm{mg} / \mathrm{L})$. 


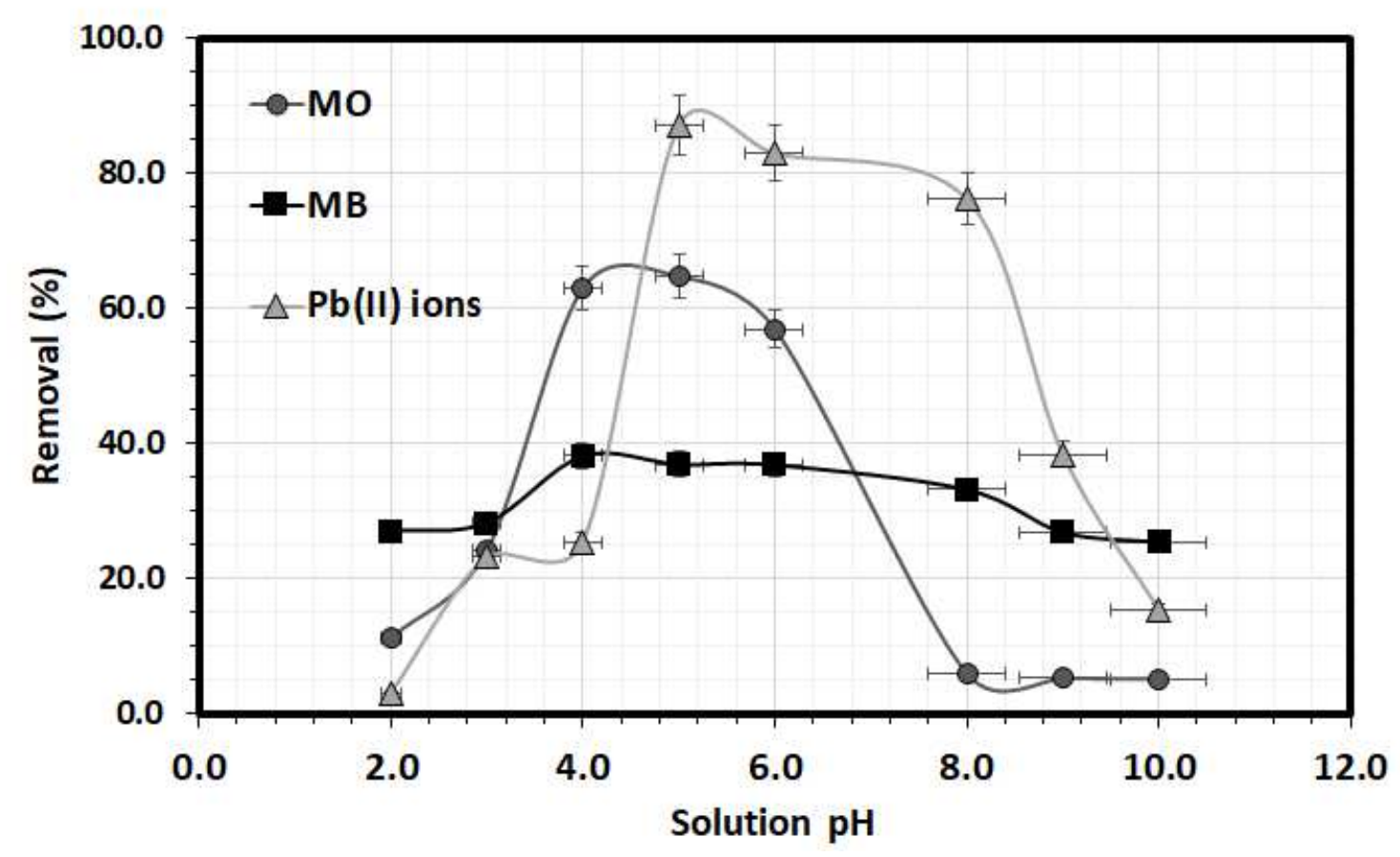

Fig. 8. Effect of the solution $\mathrm{pH}$ on the removal of $\mathrm{MB}, \mathrm{MO}$ and $\mathrm{Pb}(\mathrm{II})$ from model solution using MWG ZnO NPs. (Experimental conditions: $20.0 \mathrm{ml}$ solution, 30 minutes, pH 5.6, MWG ZnO NPs mass $15.0 \mathrm{mg}, 298 \mathrm{~K}$, and [MO] $5.0 \mathrm{mg} / \mathrm{L},[\mathrm{MB}] 5.0 \mathrm{mg} / \mathrm{L}$, $[\mathrm{Pb}(\mathrm{II})] 500 \mathrm{mg} / \mathrm{L})$. 


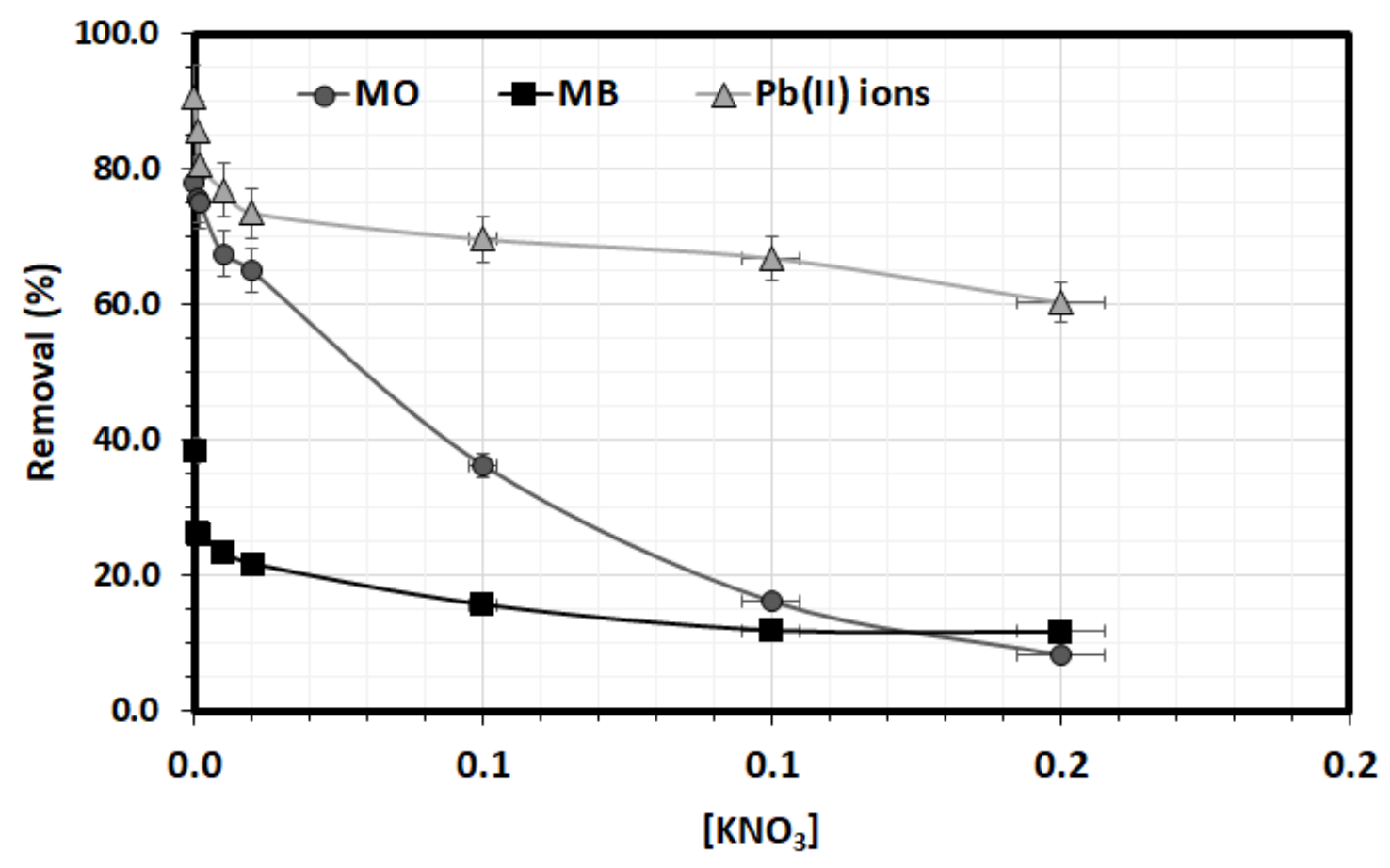

Fig. 9. Effect of the solution ionic strength on the removal of $\mathrm{MB}, \mathrm{MO}$ and $\mathrm{Pb}(\mathrm{II})$ from model solution using MWG ZnO NPs. (Experimental conditions: $20.0 \mathrm{ml}$ solution, 30 minutes, pH 5.6, MWG ZnO NPs mass $15.0 \mathrm{mg}, 298 \mathrm{~K}$, and [MO] $5.0 \mathrm{mg} / \mathrm{L}$, [MB] 5.0 $\mathrm{mg} / \mathrm{L},[\mathrm{Pb}(\mathrm{II})] 500 \mathrm{mg} / \mathrm{L})$. 


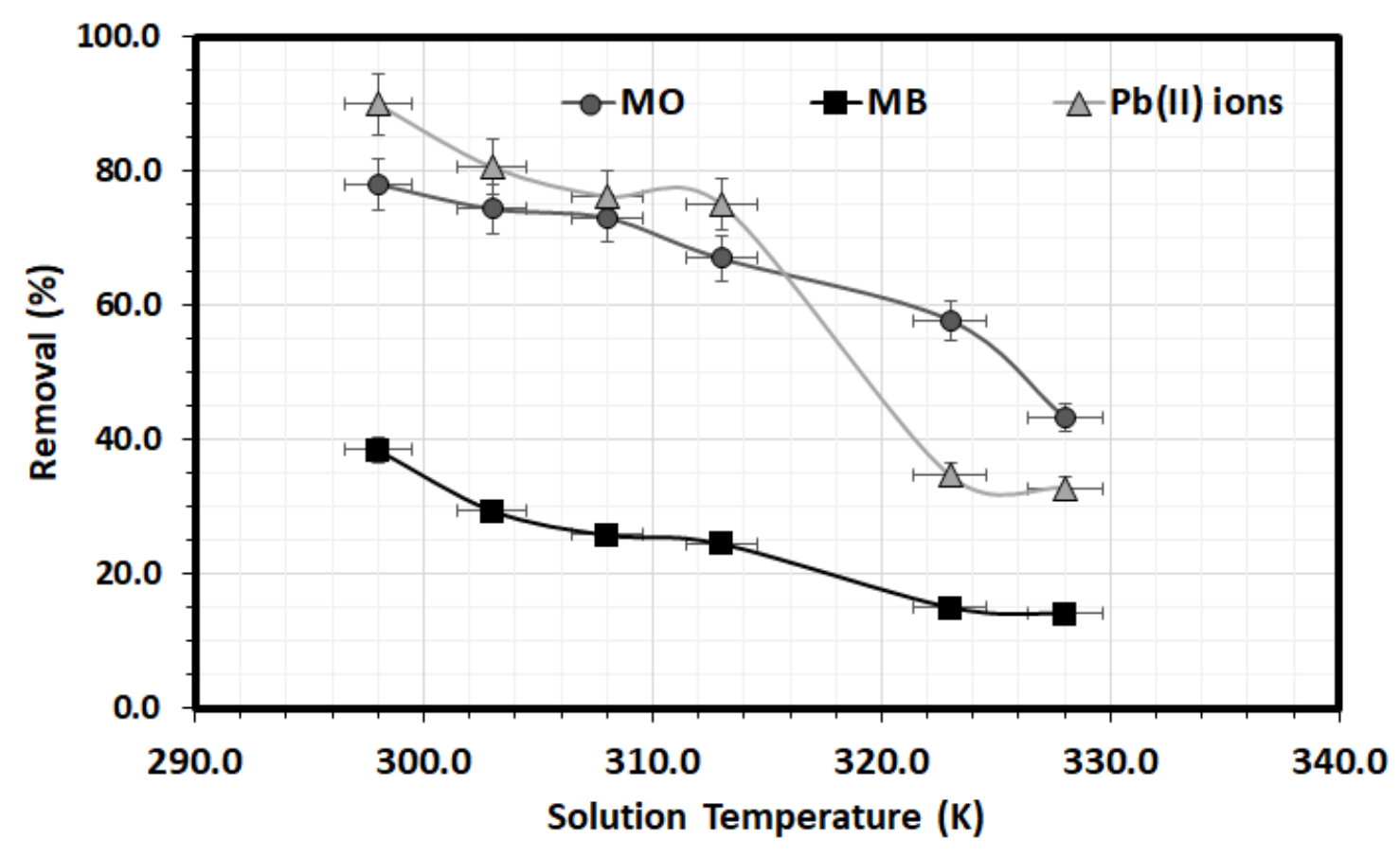

Fig. 10. Effect of the solution temperature on the removal of $\mathrm{MB}, \mathrm{MO}$ and $\mathrm{Pb}(\mathrm{II})$ from model solution using MWG ZnO NPs. (Experimental conditions: $20.0 \mathrm{ml}$ solution, 30 minutes, pH 5.6, MWG ZnO NPs mass $15.0 \mathrm{mg}, 298 \mathrm{~K}$, and [MO] $5.0 \mathrm{mg} / \mathrm{L}$, [MB] 5.0 mg/L, [Pb(II)] 500 mg/L). 


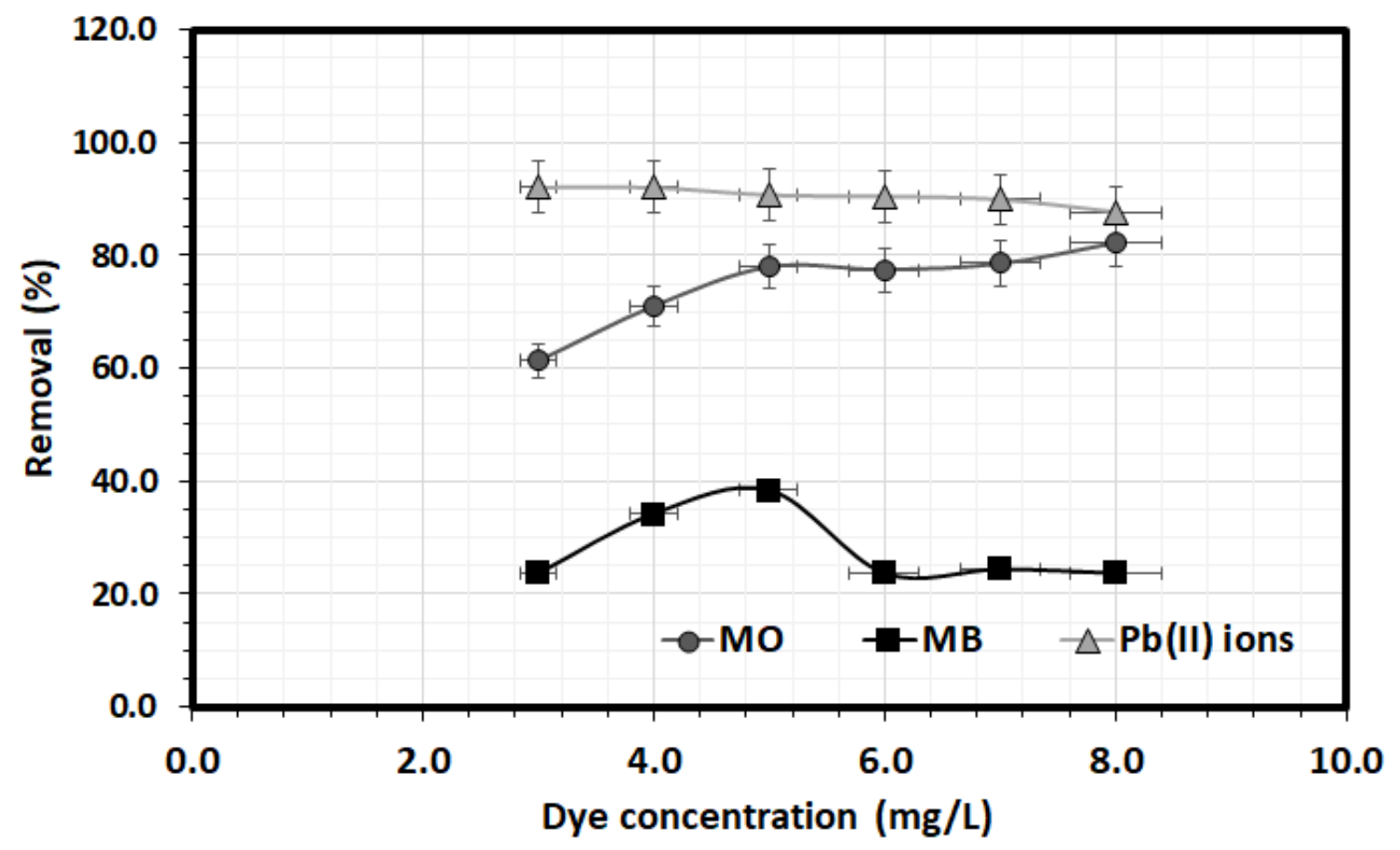

Fig. 11. Effect of varying the dye concentration on the removal of $\mathrm{MB}, \mathrm{MO}$ and $\mathrm{Pb}$ (II) from model solution using MWG ZnO NPs. (Experimental conditions: $20.0 \mathrm{ml}$ solution, 30 minutes, pH 5.6, MWG ZnO NPs mass $15.0 \mathrm{mg}, 298 \mathrm{~K}$, and (Pb(II)) $500 \mathrm{mg} / \mathrm{L})$. 


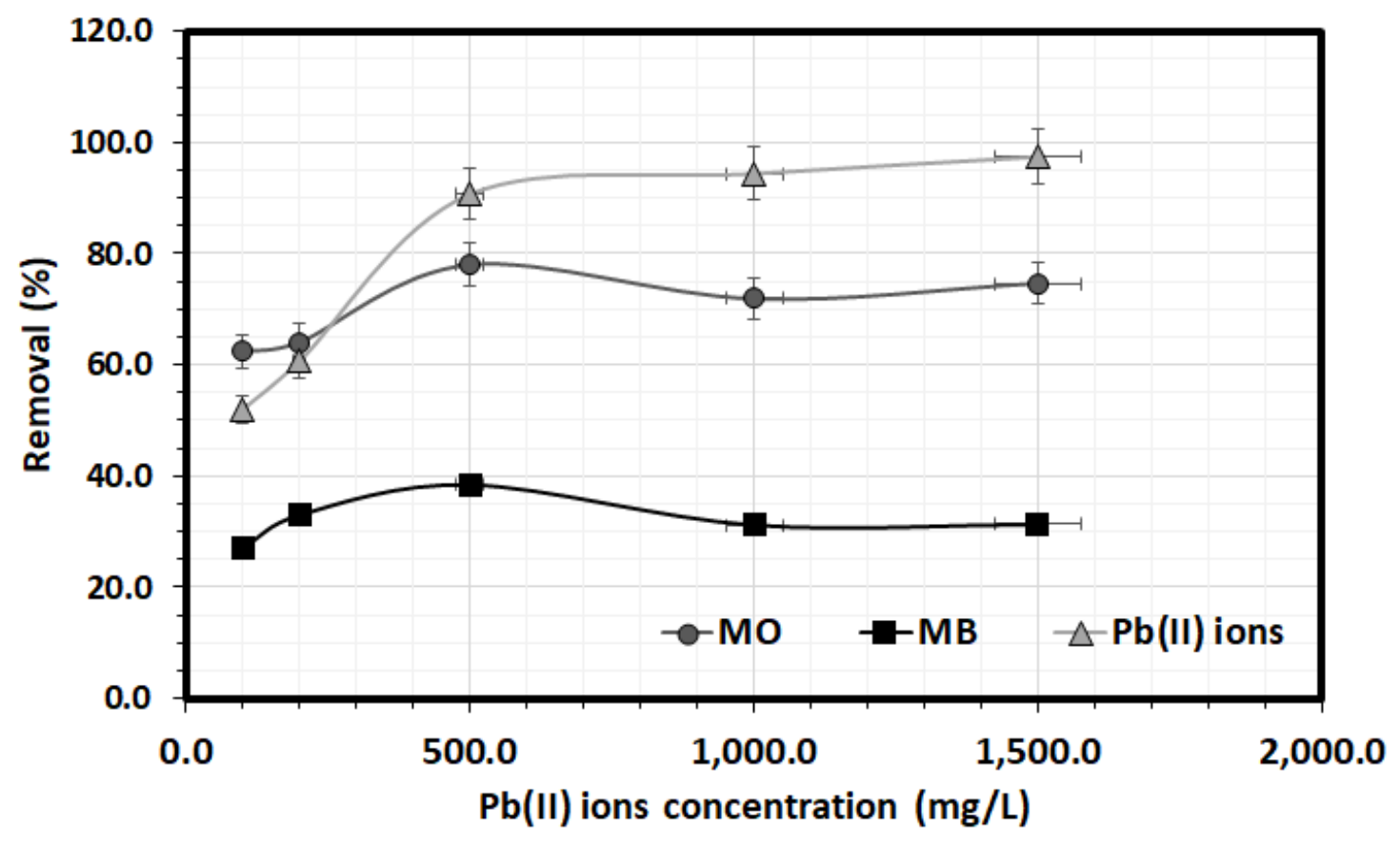

Fig. 12. Effect of varying the $\mathrm{Pb}(\mathrm{II})$ concentration on the removal of $\mathrm{MB}, \mathrm{MO}$ and $\mathrm{Pb}(\mathrm{II})$ from model solution using MWG ZnO NPs. (Experimental conditions: $20.0 \mathrm{ml}$ solution, 30 minutes, pH 5.6, MWG ZnO NPs mass $15.0 \mathrm{mg}$, $298 \mathrm{~K}$, and [MO] $5.0 \mathrm{mg} / \mathrm{L}$, [MB] $5.0 \mathrm{mg} / \mathrm{L})$. 

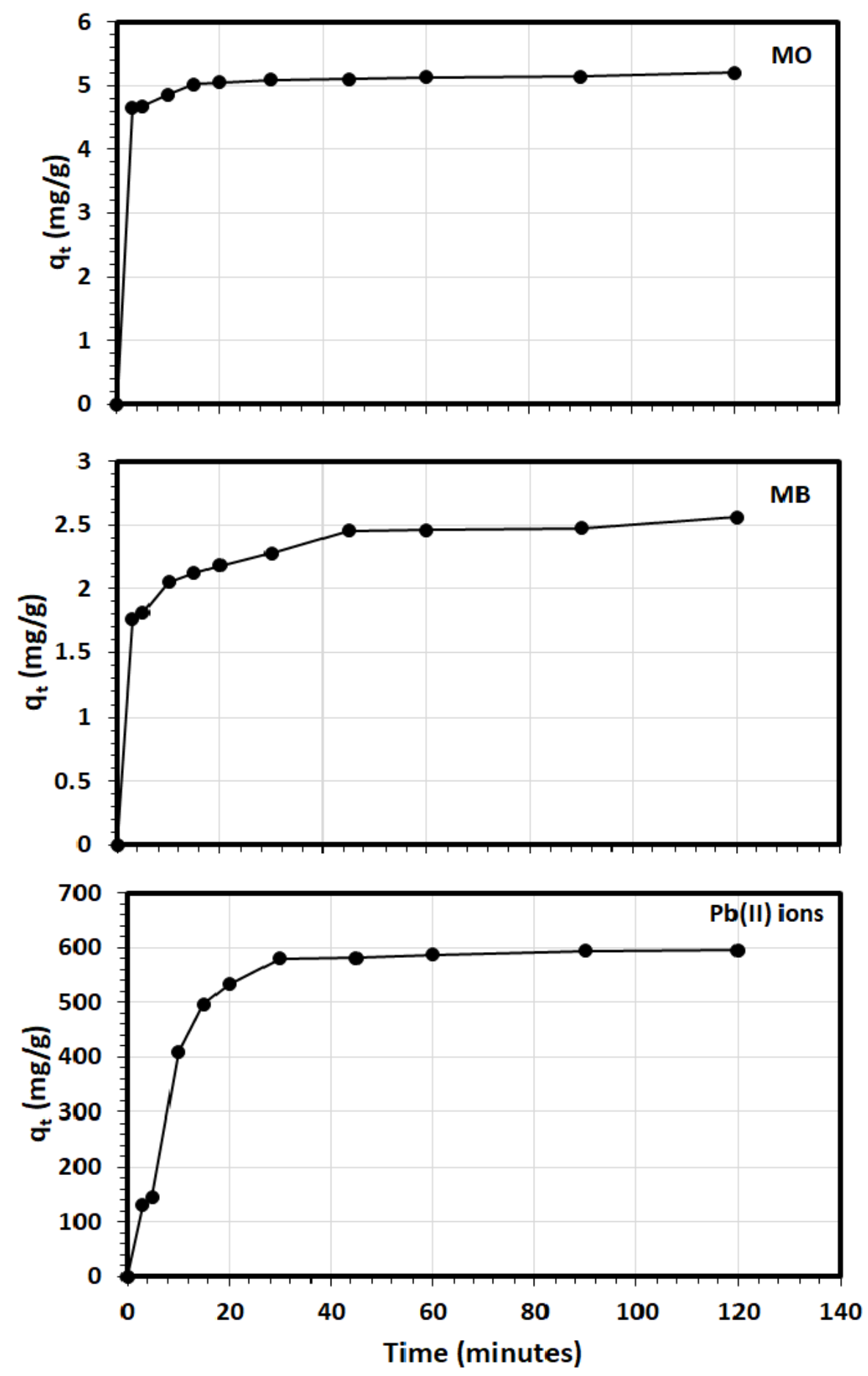

Fig. 13. The variation of the removal capacities with time for $\mathrm{MB}, \mathrm{MO}$ and $\mathrm{Pb}(\mathrm{II})$ from model solution using MWG ZnO NPs. (Experimental conditions: 20.0 ml solution, pH 5.6, MWG ZnO NPs mass $15.0 \mathrm{mg}, 298 \mathrm{~K}$, and [MO] $5.0 \mathrm{mg} / \mathrm{L}$, [MB] $5.0 \mathrm{mg} / \mathrm{L},[\mathrm{Pb}]$ $500.0 \mathrm{mg} / \mathrm{L})$. 

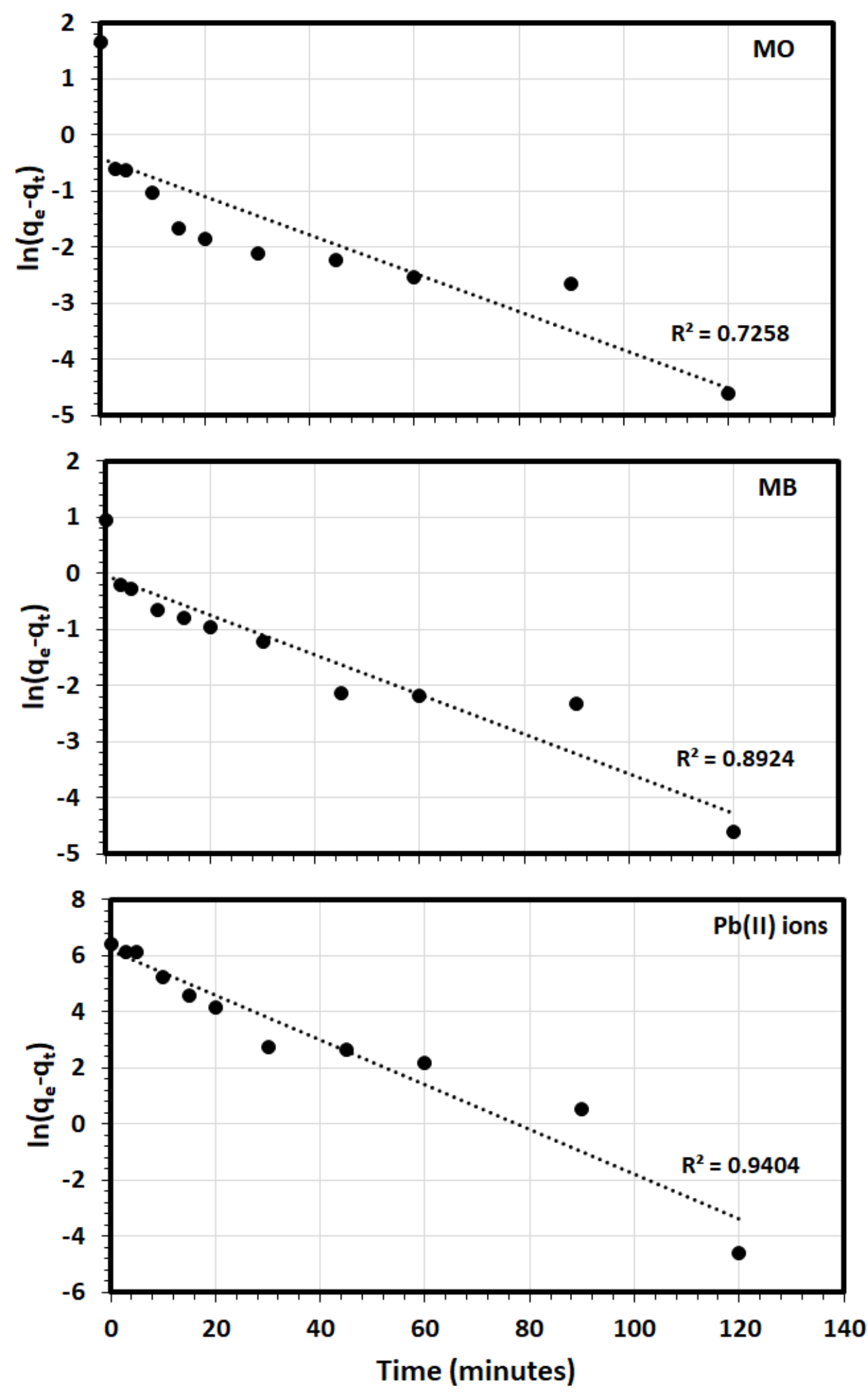

Fig. 14. The applications of the PFO kinetic model the removal of $\mathrm{MB}, \mathrm{MO}$ and $\mathrm{Pb}(\mathrm{II})$ by MWG ZnO NPs from model solution. (Experimental conditions: $20.0 \mathrm{ml}$ solution, pH 5.6, MWG ZnO NPs mass $15.0 \mathrm{mg}, 298 \mathrm{~K}$, and [MO] $5.0 \mathrm{mg} / \mathrm{L}$, [MB] $5.0 \mathrm{mg} / \mathrm{L},[\mathrm{Pb}] 500.0$ $\mathrm{mg} / \mathrm{L})$. 

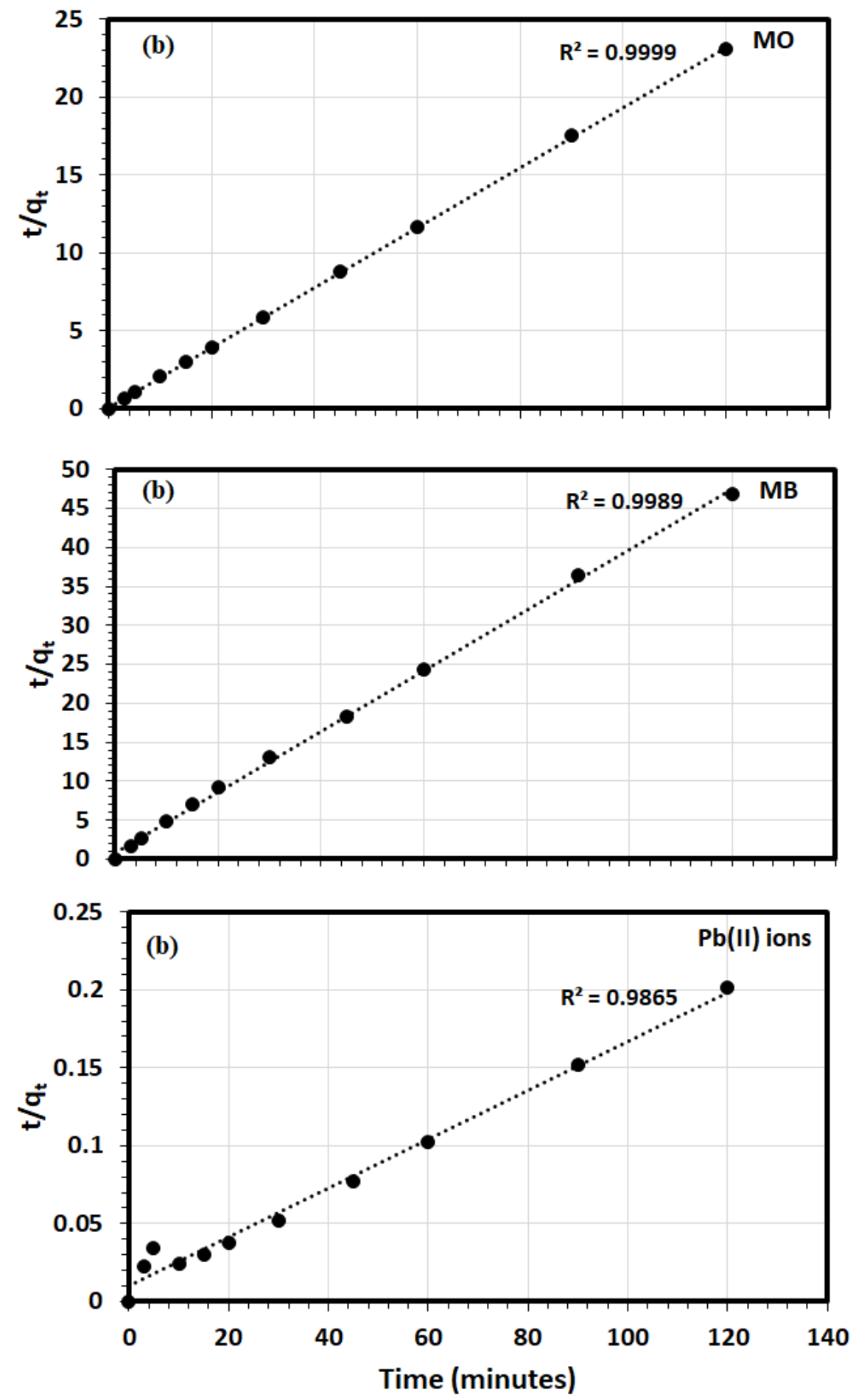

Fig. 15. The application of $\mathrm{PSO}$ kinetic model for the removal of $\mathrm{MB}, \mathrm{MO}$ and $\mathrm{Pb}(\mathrm{II})$ by MWG ZnO NPs from model solution. (Experimental conditions: $20.0 \mathrm{ml}$ solution, pH 5.6, MWG ZnO NPs mass $15.0 \mathrm{mg}, 298 \mathrm{~K}$, and [MO] $5.0 \mathrm{mg} / \mathrm{L}$, [MB] $5.0 \mathrm{mg} / \mathrm{L},[\mathrm{Pb}] 500.0$ $\mathrm{mg} / \mathrm{L})$. 


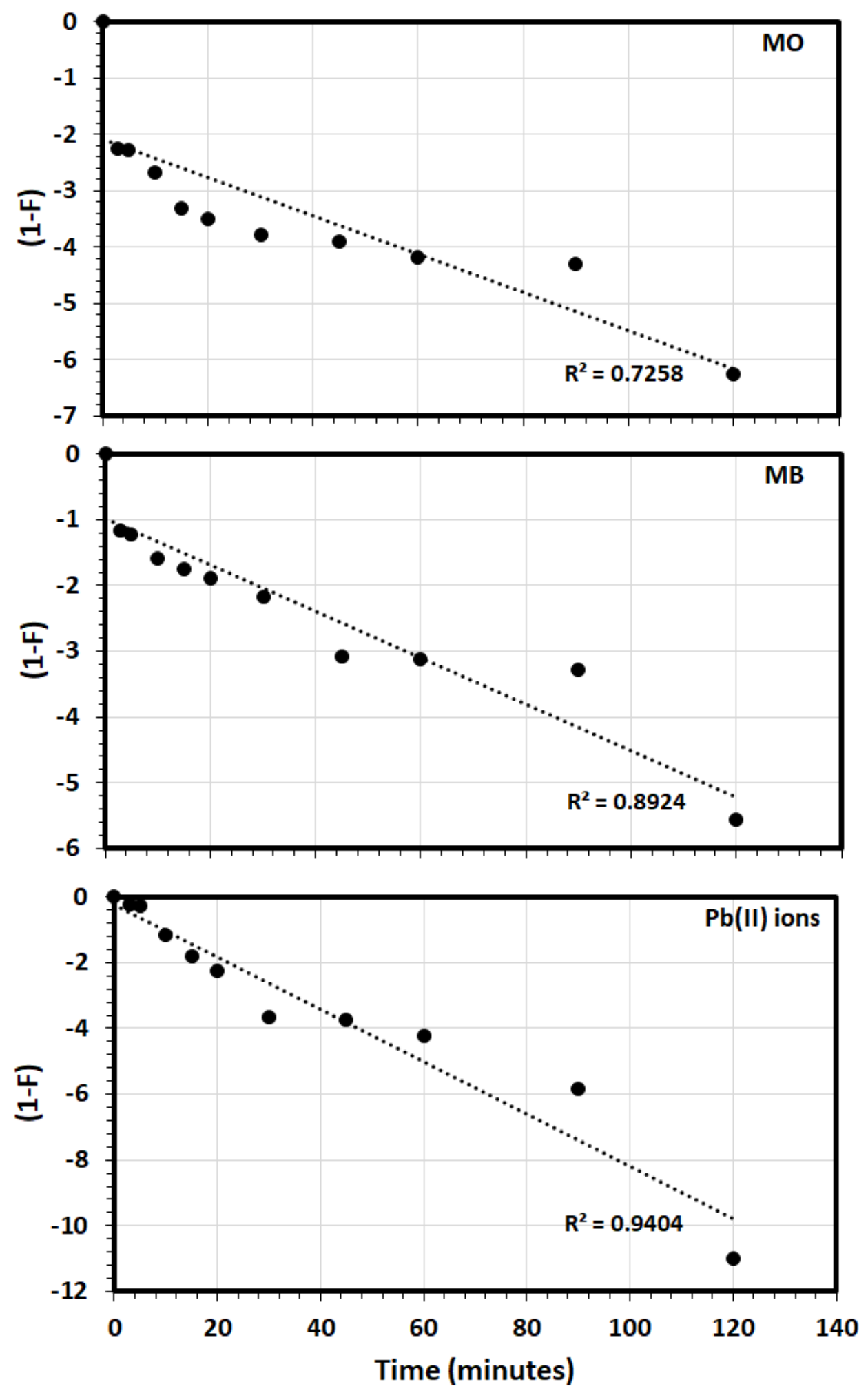

Fig. 16. The application of LFD kinetic model for the removal of $\mathrm{MB}, \mathrm{MO}$ and $\mathrm{Pb}(\mathrm{II})$ by MWG ZnO NPs from model solution. (Experimental conditions: $20.0 \mathrm{ml}$ solution, $\mathrm{pH}$ 5.6, MWG ZnO NPs mass $15.0 \mathrm{mg}, 298 \mathrm{~K}$, and [MO] $5.0 \mathrm{mg} / \mathrm{L}$, [MB] $5.0 \mathrm{mg} / \mathrm{L},[\mathrm{Pb}] 500.0$ $\mathrm{mg} / \mathrm{L})$. 

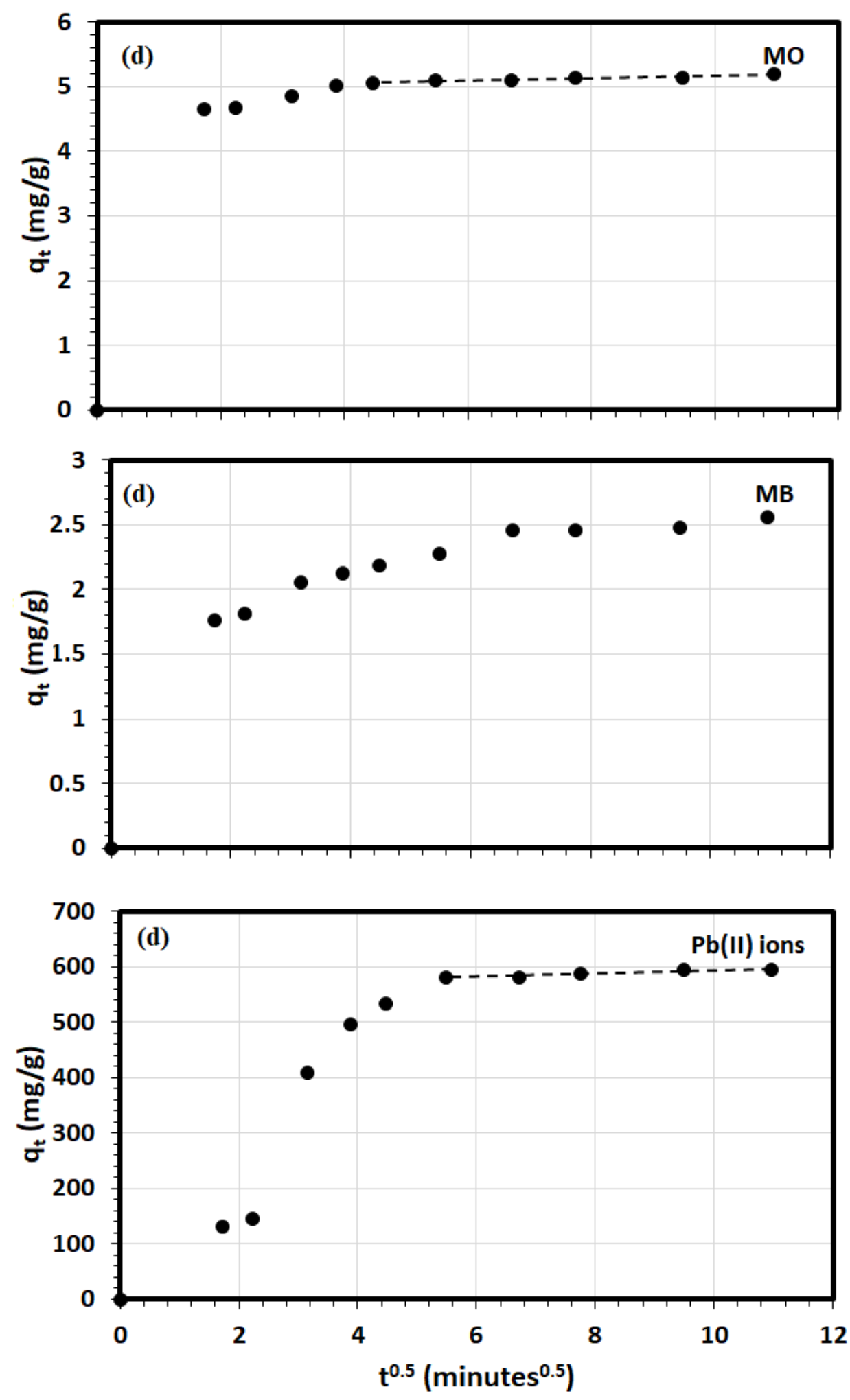

Fig. 17. The application of IPD kinetic model for the removal of $\mathrm{MB}, \mathrm{MO}$ and $\mathrm{Pb}(\mathrm{II})$ by MWG ZnO NPs from model solution. (Experimental conditions: $20.0 \mathrm{ml}$ solution, pH 5.6, MWG ZnO NPs mass $15.0 \mathrm{mg}, 298 \mathrm{~K}$, and [MO] $5.0 \mathrm{mg} / \mathrm{L}$, [MB] $5.0 \mathrm{mg} / \mathrm{L}$, [Pb] 500.0 $\mathrm{mg} / \mathrm{L})$. 


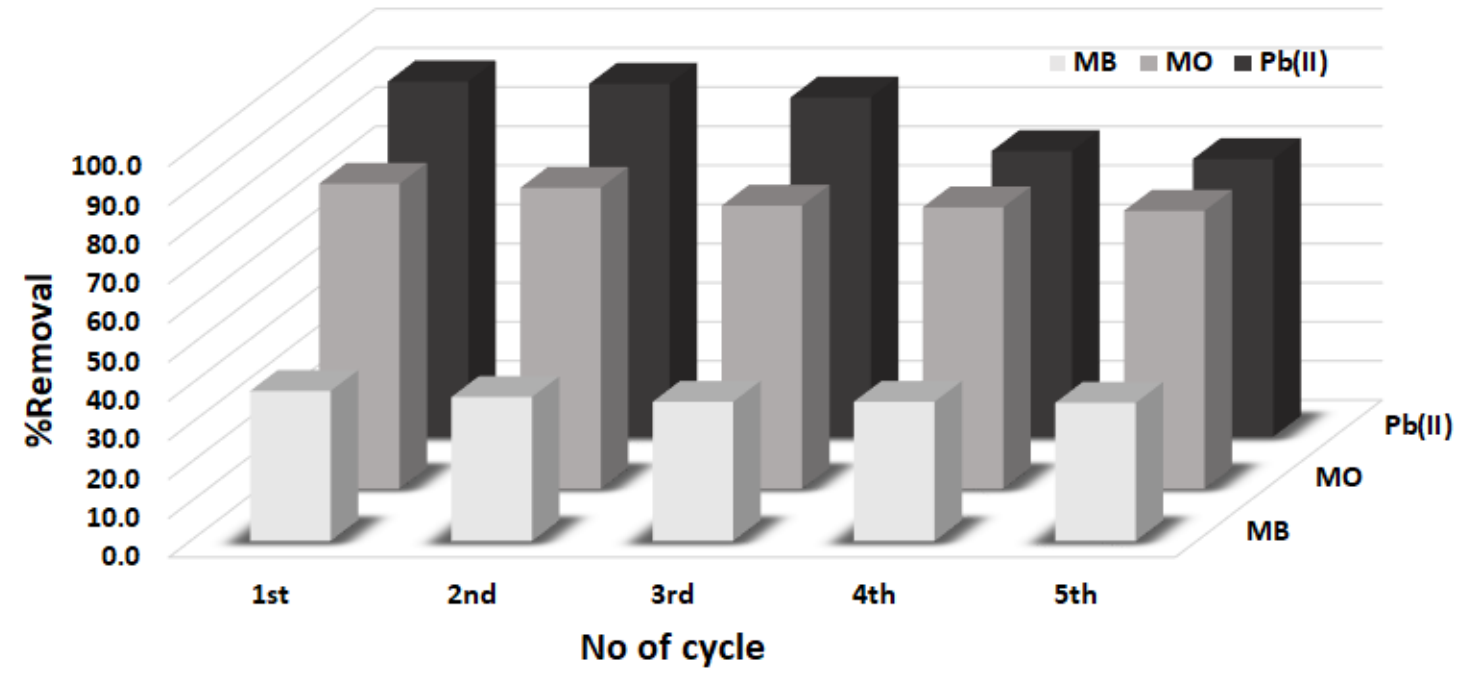

Fig. 18. Recycle study for the removal of $\mathrm{MB}, \mathrm{MO}$ and $\mathrm{Pb}(\mathrm{II})$ by $\mathrm{MWG} \mathrm{ZnO}$ NPs from model solution. (Experimental conditions: $20.0 \mathrm{ml}$ solution, pH 5.6, MWG ZnO NPs mass $15.0 \mathrm{mg}, 298 \mathrm{~K}$, and [MO] $5.0 \mathrm{mg} / \mathrm{L},[\mathrm{MB}] 5.0 \mathrm{mg} / \mathrm{L},[\mathrm{Pb}] 500.0 \mathrm{mg} / \mathrm{L})$. 


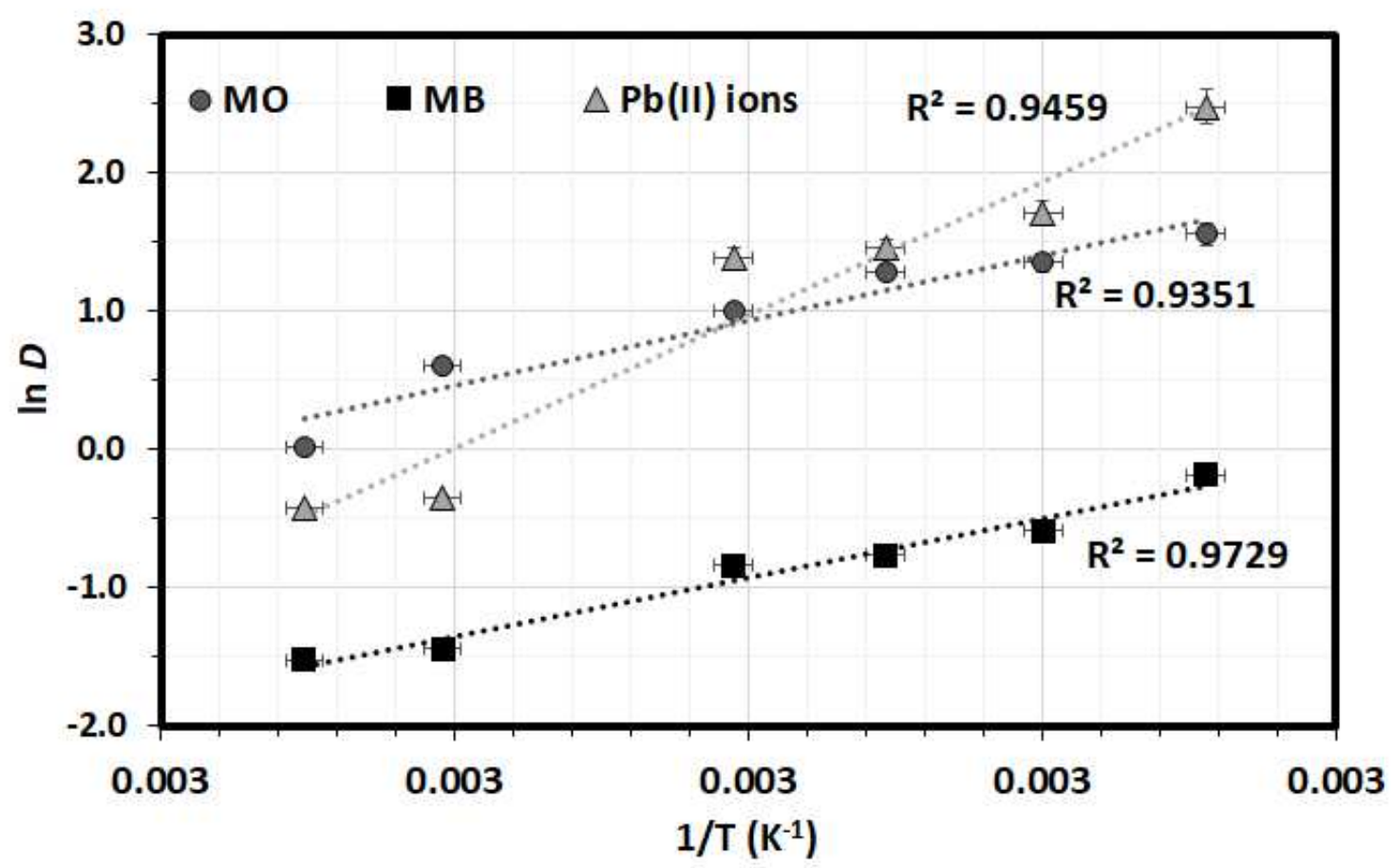

Fig. 19. The estimation of thermodynamic parameters for $\mathrm{MO}, \mathrm{MB}$, and $\mathrm{Pb}$ (II) ions removal by the MWG ZnO NPs from model solution. (Experimental conditions: $20.0 \mathrm{ml}$ solution, pH 5.6, MWG ZnO NPs mass $15.0 \mathrm{mg}$, and [MO] $5.0 \mathrm{mg} / \mathrm{L}$, [MB] $5.0 \mathrm{mg} / \mathrm{L}$, $[\mathrm{Pb}] 500.0 \mathrm{mg} / \mathrm{L})$. 
Figures

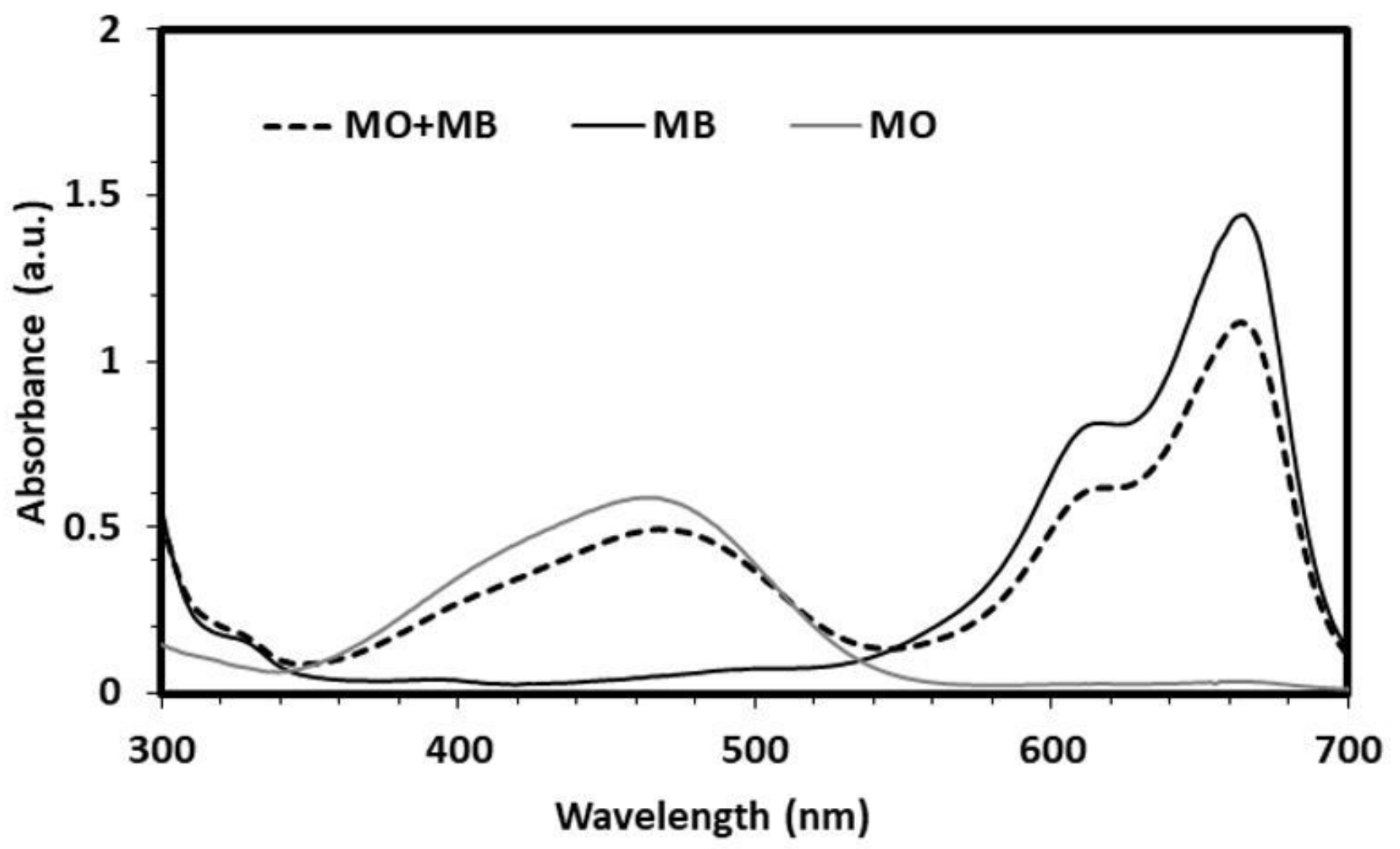

Figure 1

The Uv-vis spectra of $\mathrm{MO}$, and $\mathrm{MB}$ in aqueous solution. 

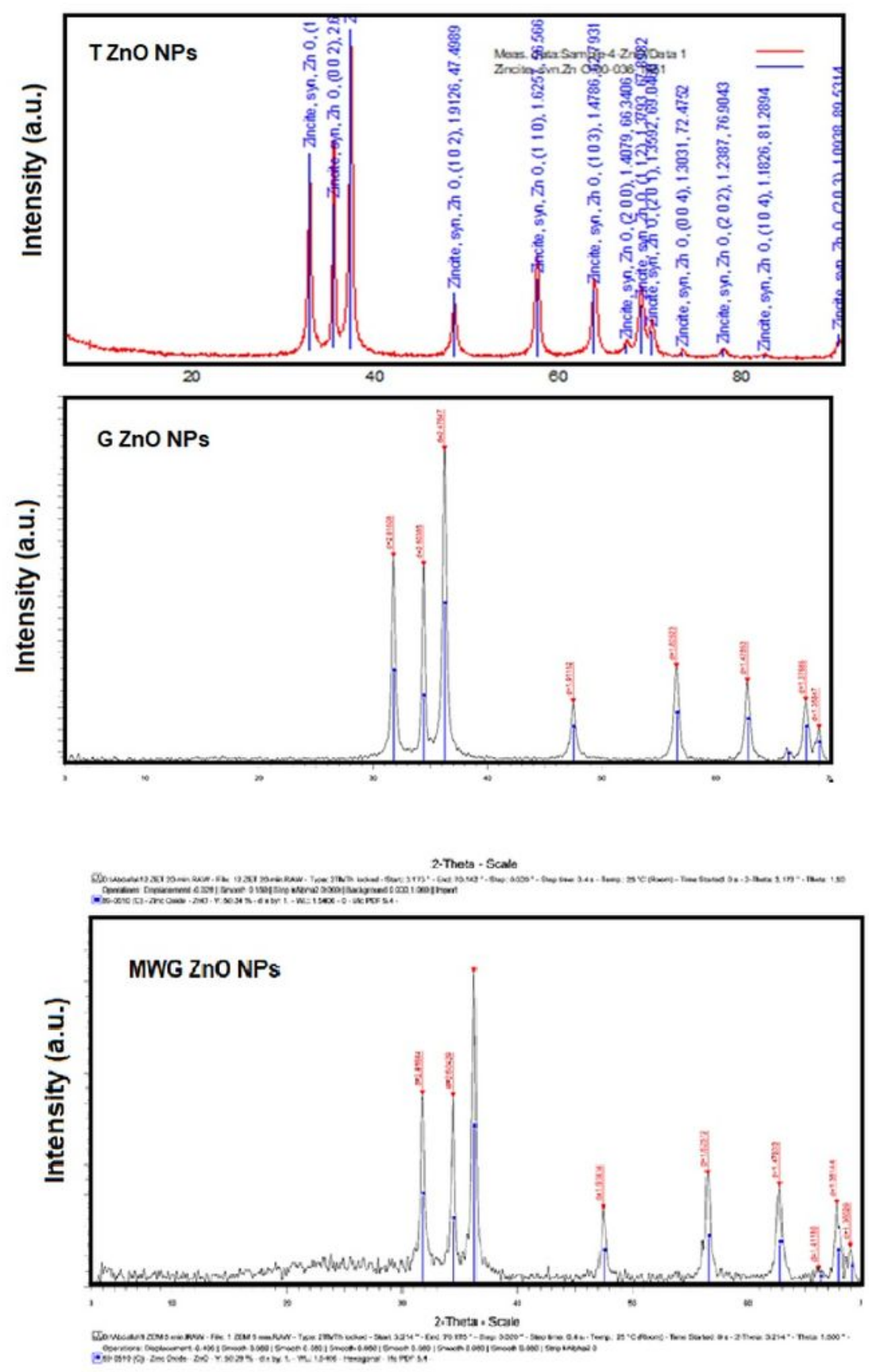

Figure 2

XRD patterns of different ZnO NPs. 

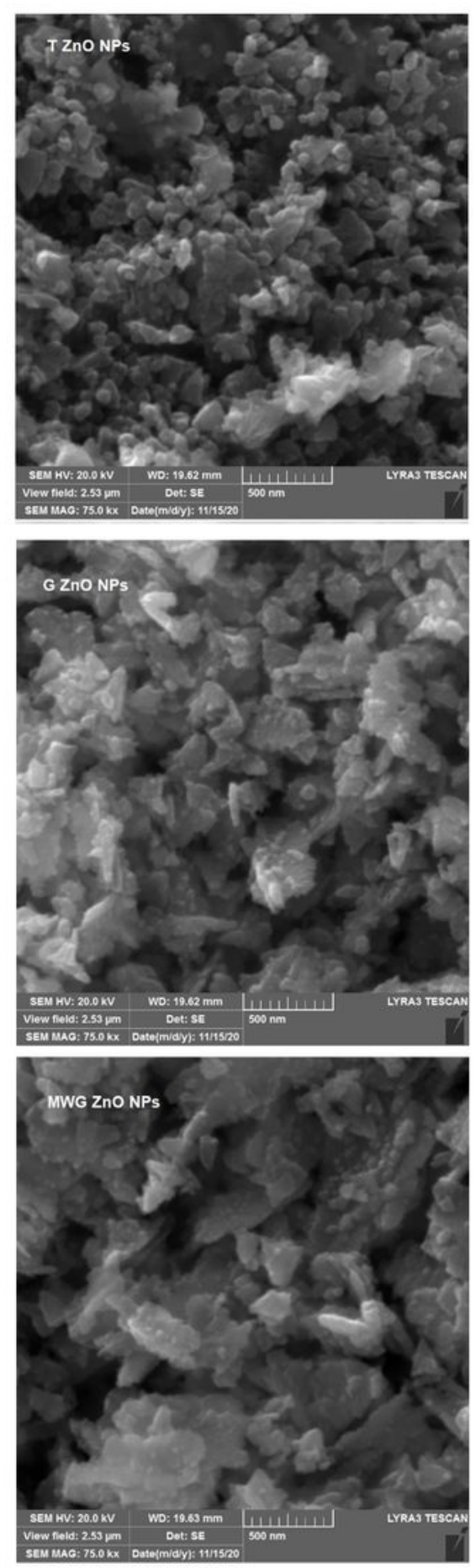

Figure 3

SEM images of different ZnO NPs. 

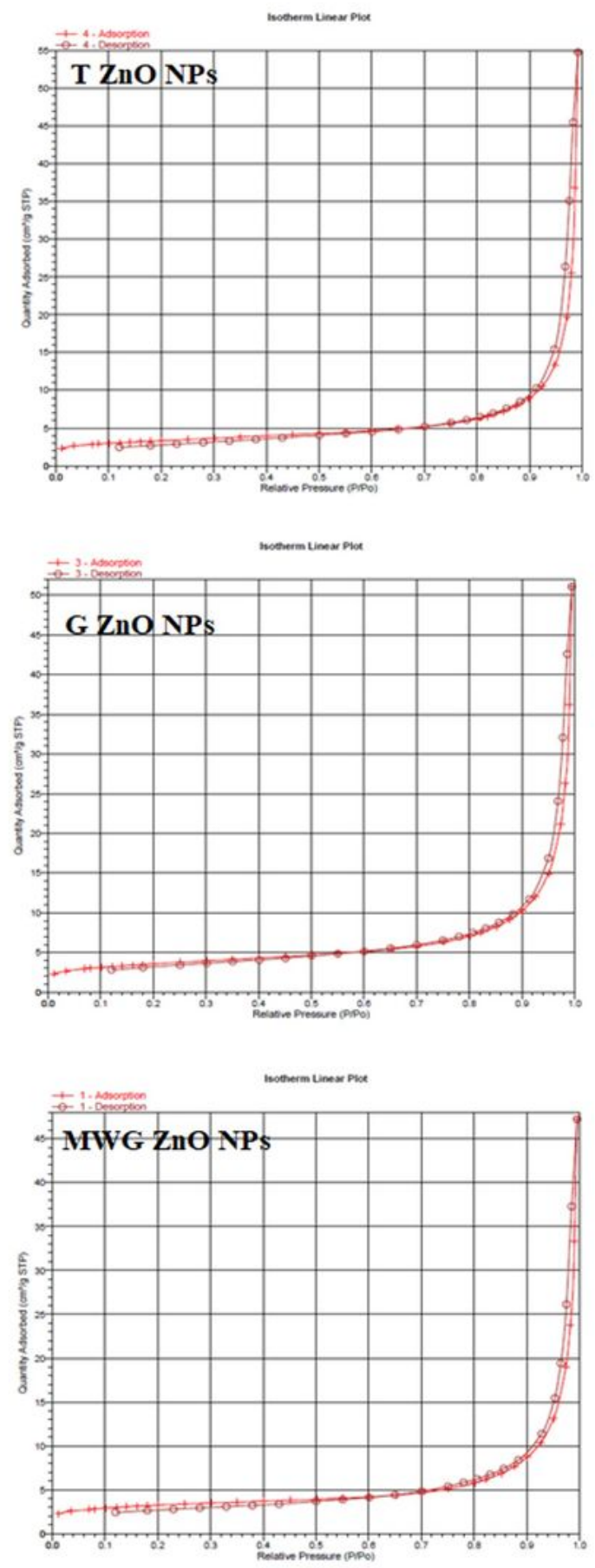

Figure 4

N2 adsorption/desorption isotherms of different ZnO NPs. 


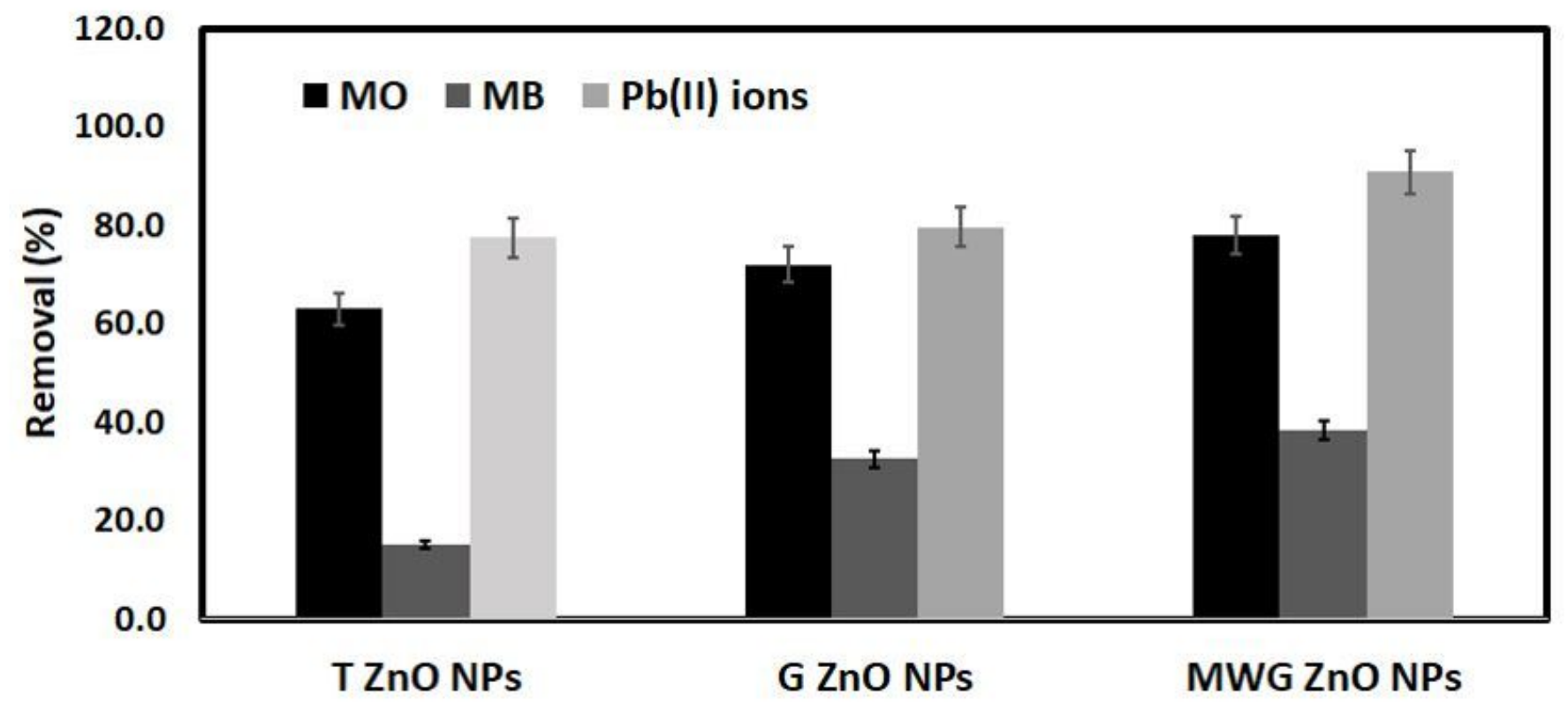

Figure 5

The removal efficacies of $\mathrm{MB}, \mathrm{MO}$ and $\mathrm{Pb}$ (II) by different ZnO NPs; T ZnO NPs, G ZnO NPs, and MWG ZnO NPs, from model solution. (Experimental conditions: $20.0 \mathrm{ml}$ solution, mass $15 \mathrm{mg}, \mathrm{pH}$ 5.6, 30 minutes, $298 \mathrm{~K}$, and [MO] $5.0 \mathrm{mg} / \mathrm{L}$, [MB] $5.0 \mathrm{mg} / \mathrm{L},[\mathrm{Pb}(\mathrm{II})] 500 \mathrm{mg} / \mathrm{L})$. 


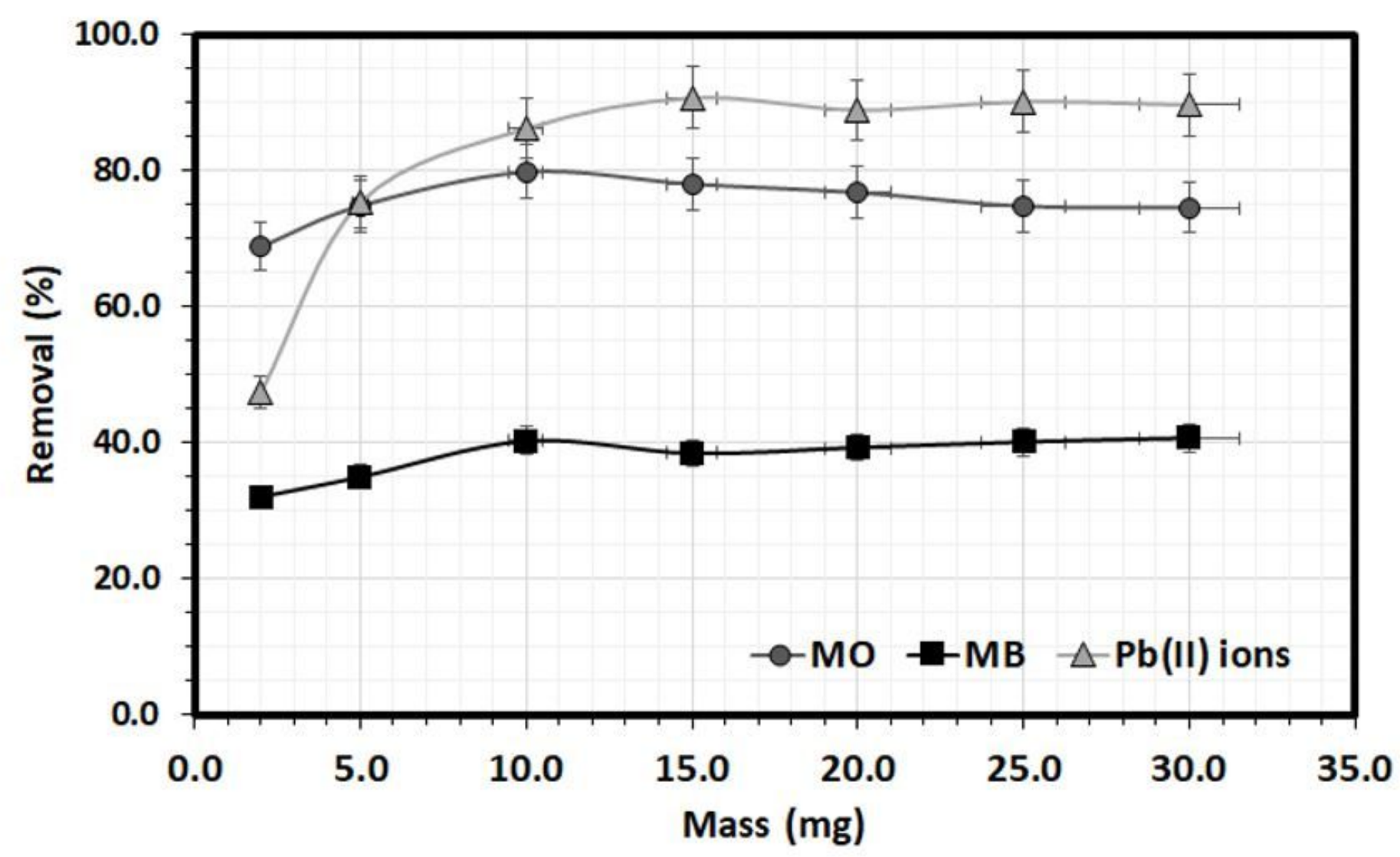

Figure 6

Effect of the MWG ZnO NPs mass on the removal of $\mathrm{MB}, \mathrm{MO}$ and $\mathrm{Pb}(\mathrm{II})$ from model solution.

(Experimental conditions: $20.0 \mathrm{ml}$ solution, pH 5.6, 30 minutes, $298 \mathrm{~K}$, and [MO] $5.0 \mathrm{mg} / \mathrm{L}$, [MB] $5.0 \mathrm{mg} / \mathrm{L}$, $[\mathrm{Pb}(\mathrm{II})] 500 \mathrm{mg} / \mathrm{L})$. 


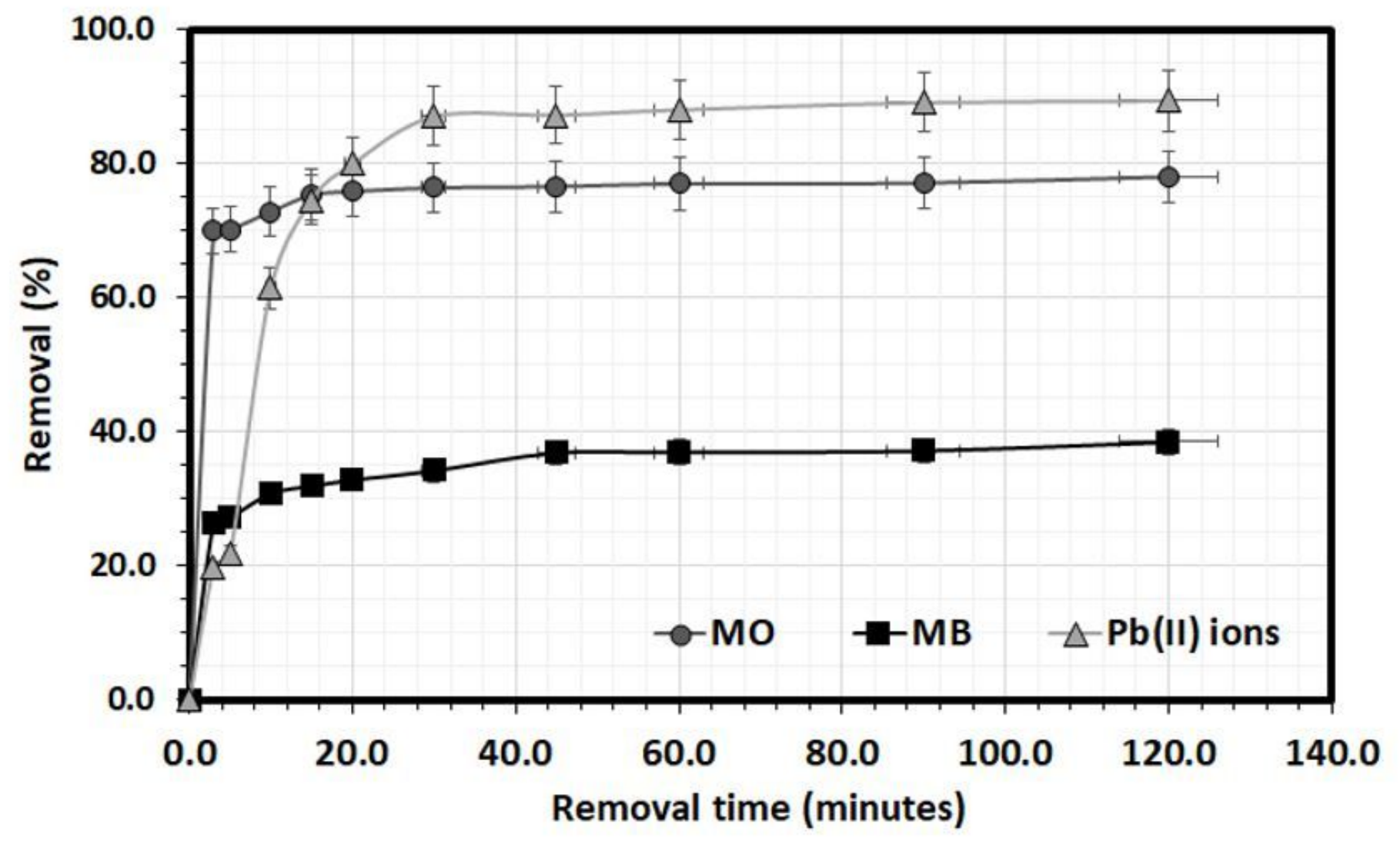

Figure 7

Effect of the removal time on the removal of $\mathrm{MB}, \mathrm{MO}$ and $\mathrm{Pb}$ (II) from model solution using MWG $\mathrm{ZnO}$ NPs. (Experimental conditions: $20.0 \mathrm{ml}$ solution, pH 5.6, MWG ZnO NPs mass $15.0 \mathrm{mg}$, $298 \mathrm{~K}$, and [MO] $5.0 \mathrm{mg} / \mathrm{L},[\mathrm{MB}] 5.0 \mathrm{mg} / \mathrm{L},[\mathrm{Pb}(\mathrm{II})] 500 \mathrm{mg} / \mathrm{L})$. 


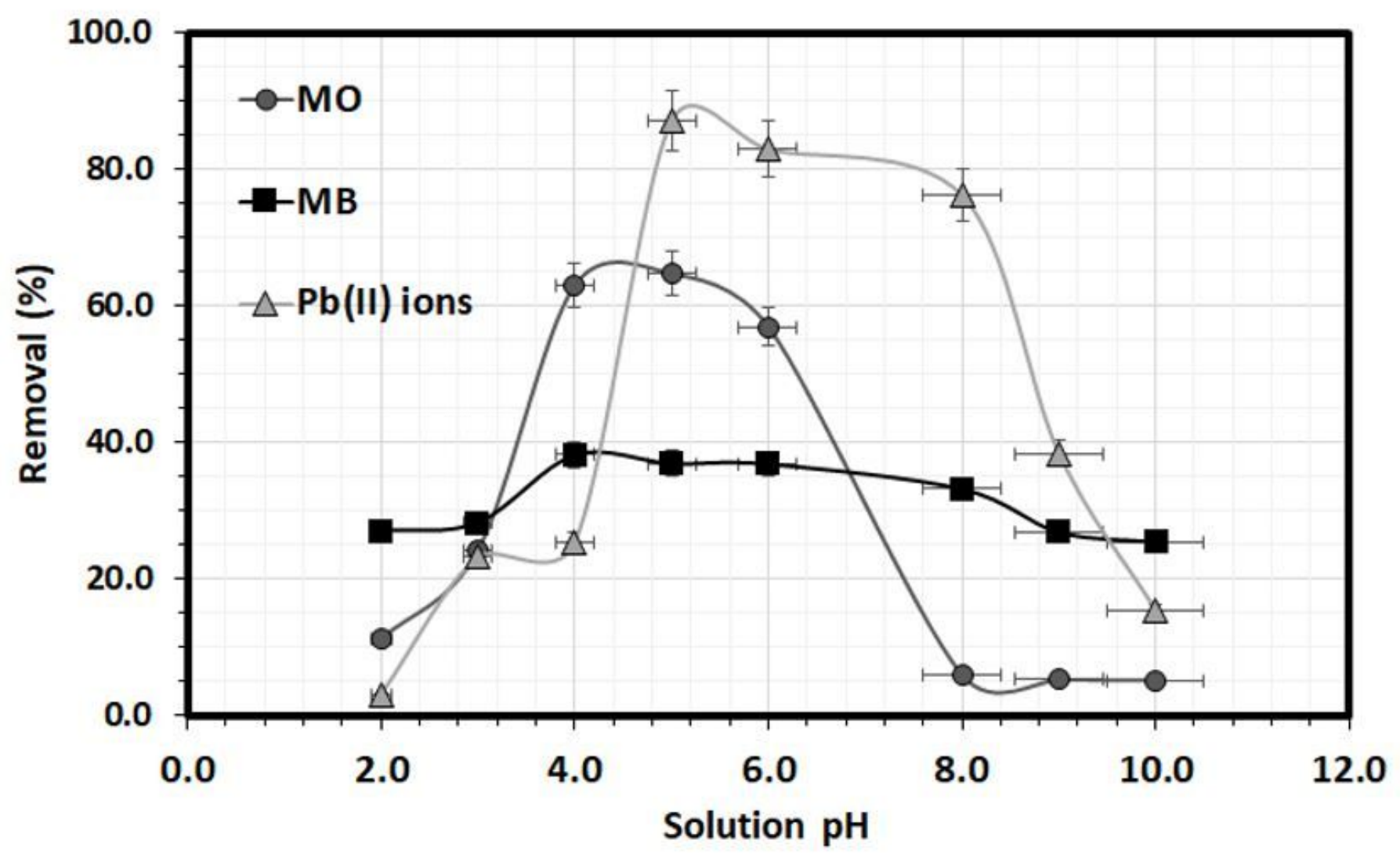

Figure 8

Effect of the solution $\mathrm{pH}$ on the removal of $\mathrm{MB}, \mathrm{MO}$ and $\mathrm{Pb}$ (II) from model solution using MWG ZnO NPs. (Experimental conditions: $20.0 \mathrm{ml}$ solution, 30 minutes, pH 5.6, MWG ZnO NPs mass $15.0 \mathrm{mg}, 298 \mathrm{~K}$, and [MO] $5.0 \mathrm{mg} / \mathrm{L},[\mathrm{MB}] 5.0 \mathrm{mg} / \mathrm{L},[\mathrm{Pb}(\mathrm{II})] 500 \mathrm{mg} / \mathrm{L})$. 


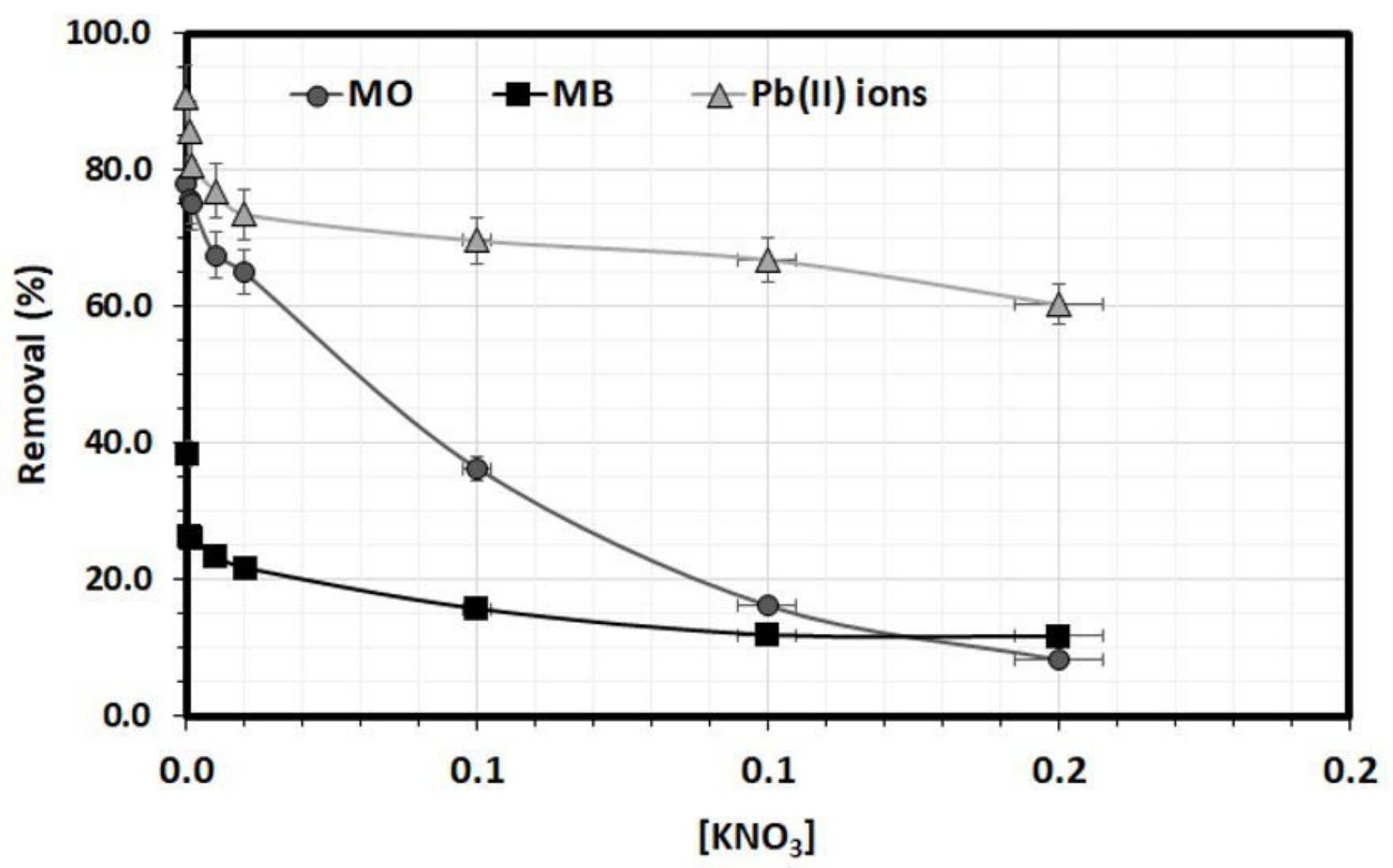

Figure 9

Effect of the solution ionic strength on the removal of $\mathrm{MB}, \mathrm{MO}$ and $\mathrm{Pb}$ (II) from model solution using MWG ZnO NPs. (Experimental conditions: $20.0 \mathrm{ml}$ solution, 30 minutes, pH 5.6, MWG ZnO NPs mass $15.0 \mathrm{mg}$, $298 \mathrm{~K}$, and [MO] $5.0 \mathrm{mg} / \mathrm{L},[\mathrm{MB}] 5.0 \mathrm{mg} / \mathrm{L},[\mathrm{Pb}(\mathrm{II})] 500 \mathrm{mg} / \mathrm{L})$. 


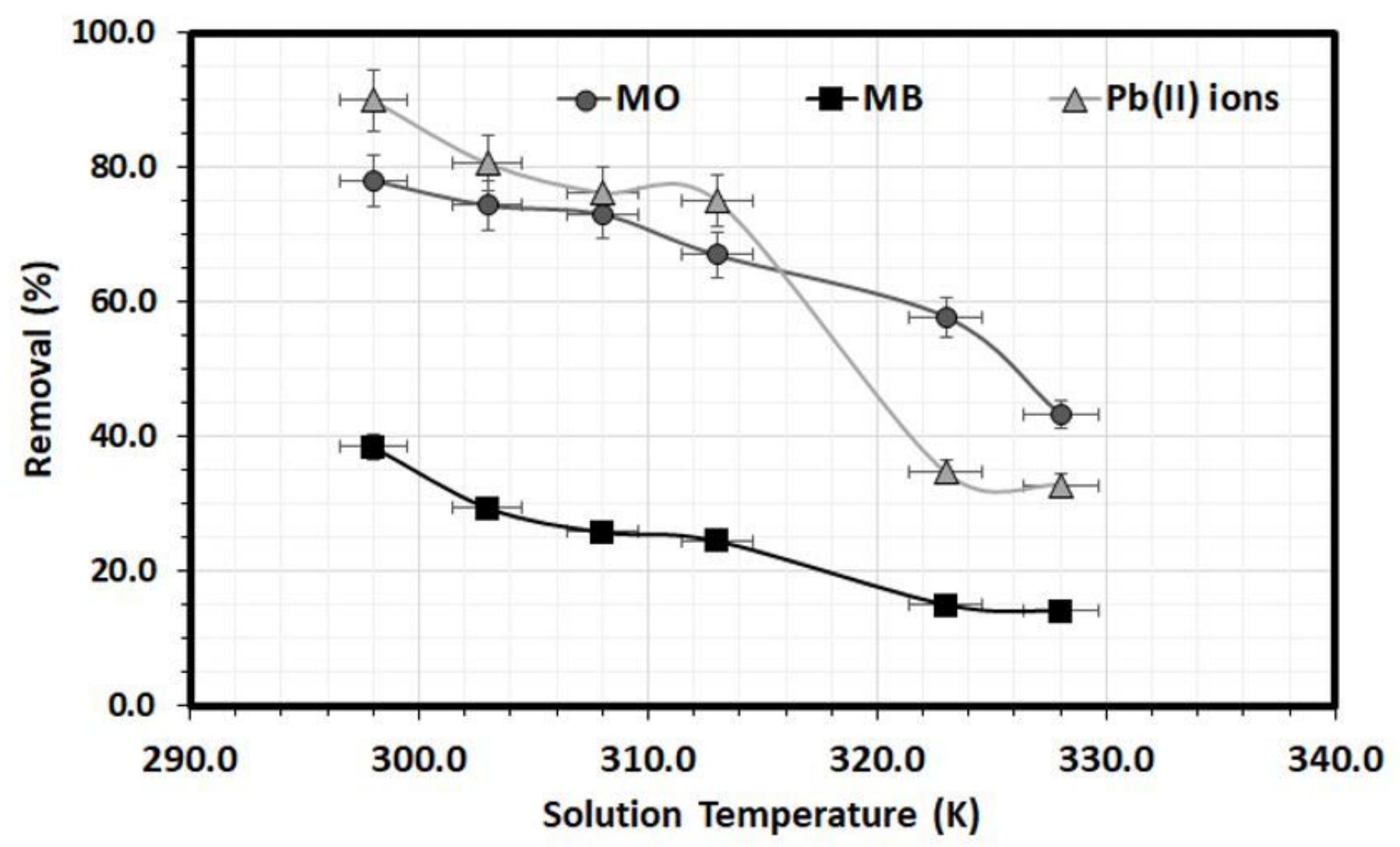

Figure 10

Effect of the solution temperature on the removal of $\mathrm{MB}, \mathrm{MO}$ and $\mathrm{Pb}(\mathrm{II})$ from model solution using MWG ZnO NPs. (Experimental conditions: $20.0 \mathrm{ml}$ solution, 30 minutes, pH 5.6, MWG ZnO NPs mass $15.0 \mathrm{mg}$, $298 \mathrm{~K}$, and [MO] $5.0 \mathrm{mg} / \mathrm{L},[\mathrm{MB}] 5.0 \mathrm{mg} / \mathrm{L}$, [Pb(II)] $500 \mathrm{mg} / \mathrm{L})$. 


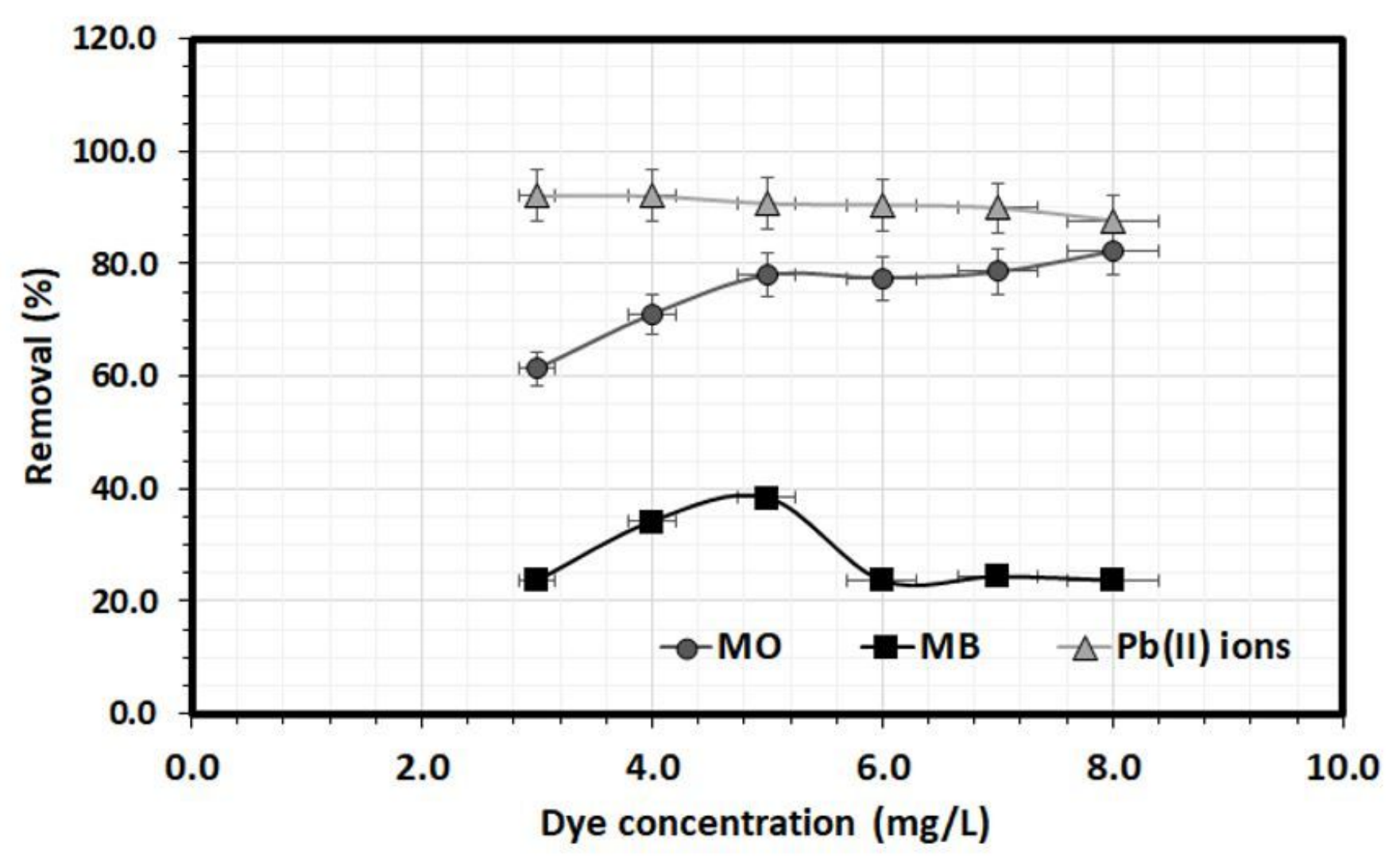

Figure 11

Effect of varying the dye concentration on the removal of $\mathrm{MB}, \mathrm{MO}$ and $\mathrm{Pb}(\mathrm{II})$ from model solution using MWG ZnO NPs. (Experimental conditions: $20.0 \mathrm{ml}$ solution, 30 minutes, pH 5.6, MWG ZnO NPs mass 15.0 $\mathrm{mg}, 298 \mathrm{~K}$, and $(\mathrm{Pb}(\mathrm{II})) 500 \mathrm{mg} / \mathrm{L})$. 


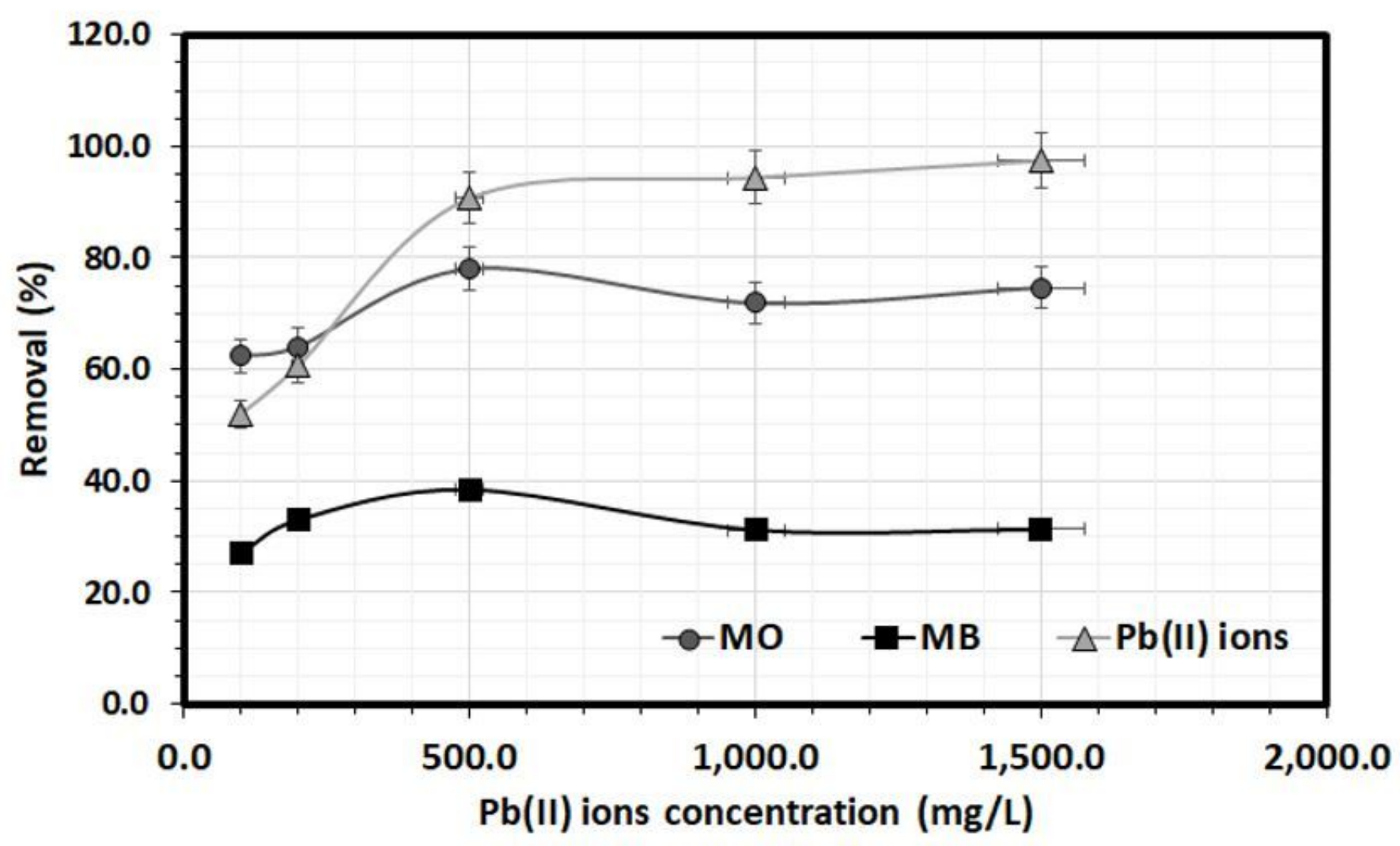

Figure 12

Effect of varying the $\mathrm{Pb}(\mathrm{II})$ concentration on the removal of $\mathrm{MB}, \mathrm{MO}$ and $\mathrm{Pb}$ (II) from model solution using MWG ZnO NPs. (Experimental conditions: 20.0 ml solution, 30 minutes, pH 5.6, MWG ZnO NPs mass 15.0 $\mathrm{mg}, 298 \mathrm{~K}$, and [MO] $5.0 \mathrm{mg} / \mathrm{L},[\mathrm{MB}] 5.0 \mathrm{mg} / \mathrm{L})$. 

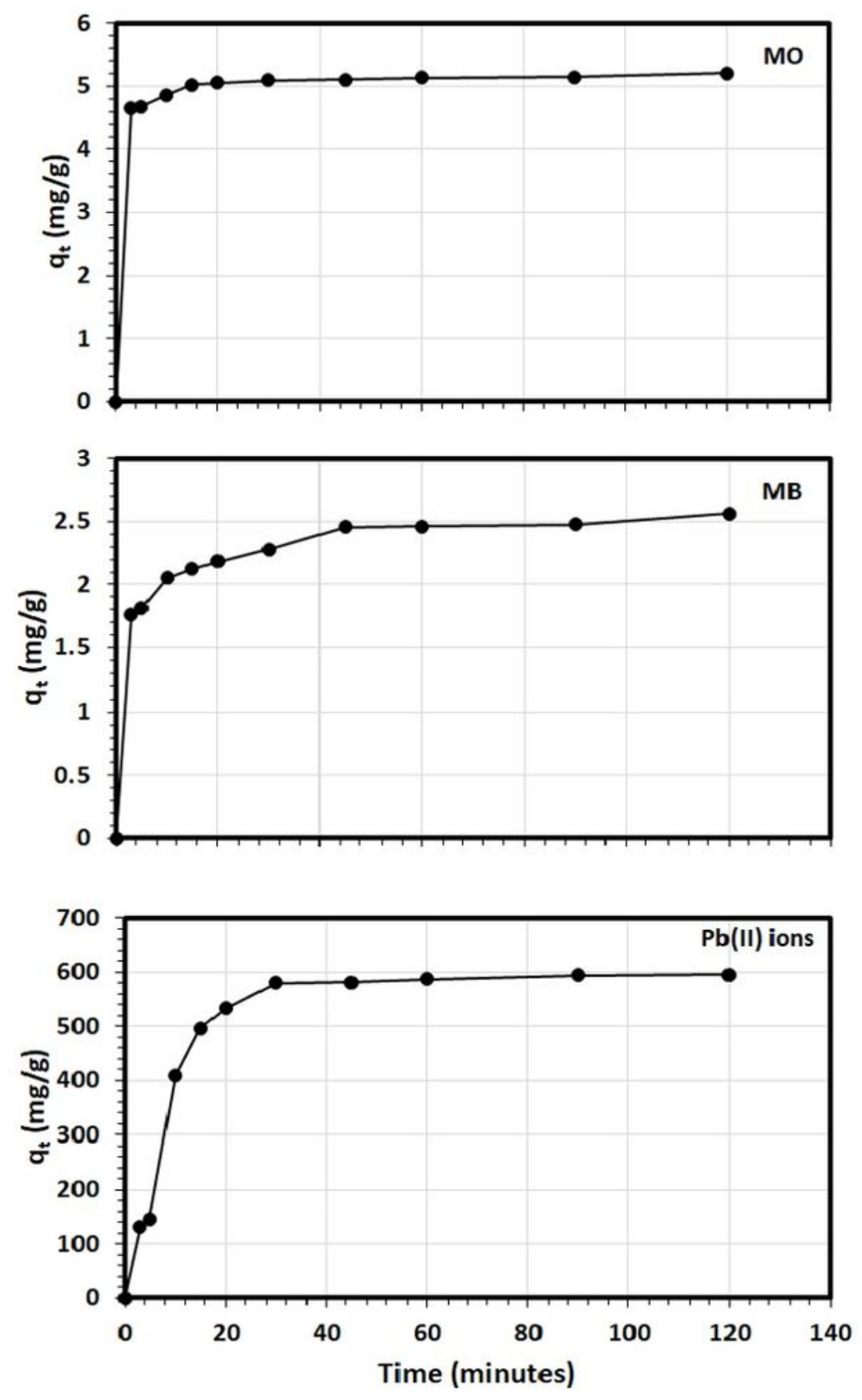

Figure 13

The variation of the removal capacities with time for $\mathrm{MB}, \mathrm{MO}$ and $\mathrm{Pb}(\mathrm{II})$ from model solution using MWG ZnO NPs. (Experimental conditions: $20.0 \mathrm{ml}$ solution, pH 5.6, MWG ZnO NPs mass $15.0 \mathrm{mg}$, $298 \mathrm{~K}$, and [MO] $5.0 \mathrm{mg} / \mathrm{L},[\mathrm{MB}] 5.0 \mathrm{mg} / \mathrm{L},[\mathrm{Pb}] 500.0 \mathrm{mg} / \mathrm{L}$ ). 

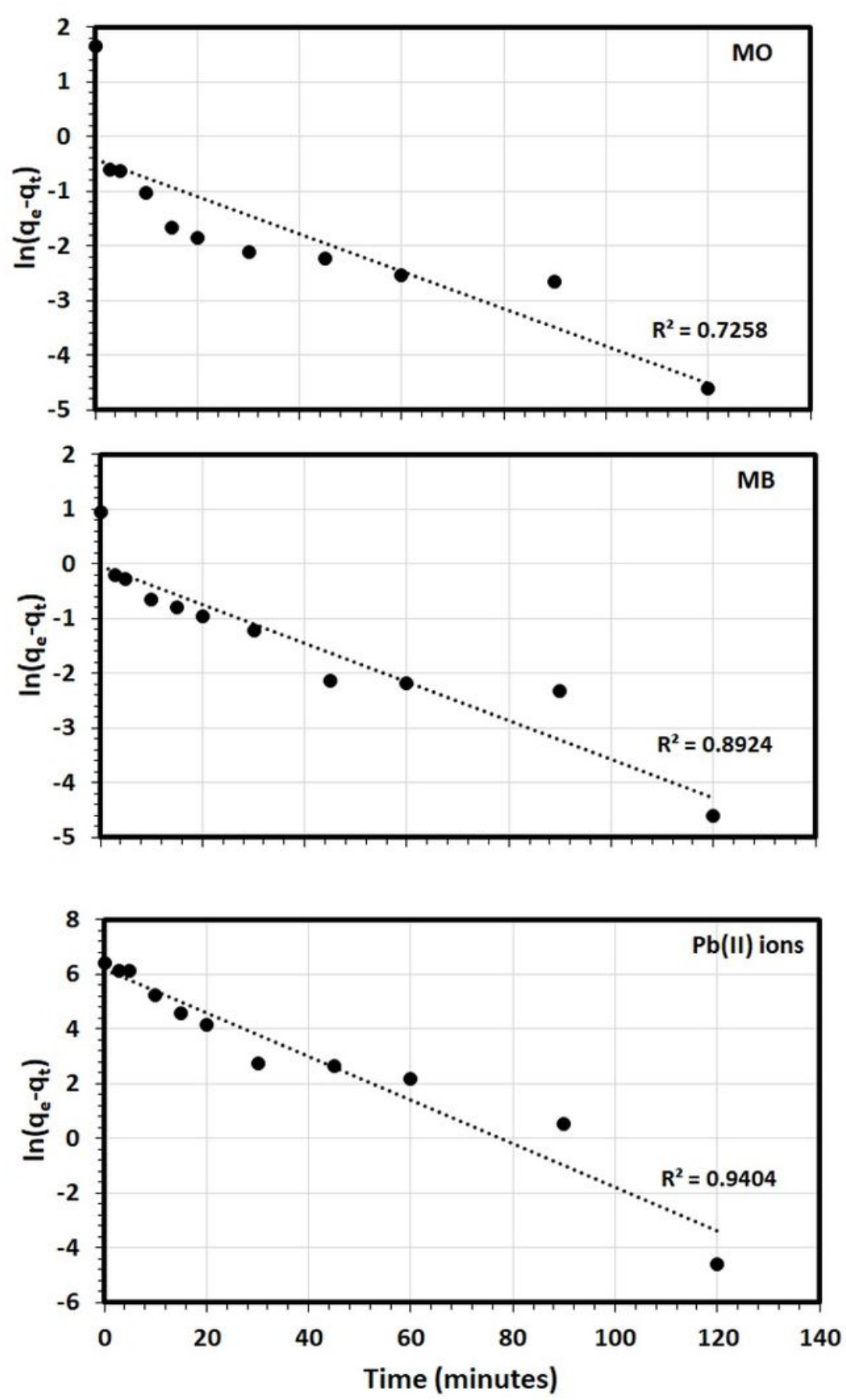

Figure 14

The applications of the PFO kinetic model the removal of MB, MO and Pb(II) by MWG ZnO NPs from model solution. (Experimental conditions: $20.0 \mathrm{ml}$ solution, pH 5.6, MWG ZnO NPs mass $15.0 \mathrm{mg}$, $298 \mathrm{~K}$, and [MO] $5.0 \mathrm{mg} / \mathrm{L},[\mathrm{MB}] 5.0 \mathrm{mg} / \mathrm{L},[\mathrm{Pb}] 500.0 \mathrm{mg} / \mathrm{L})$. 

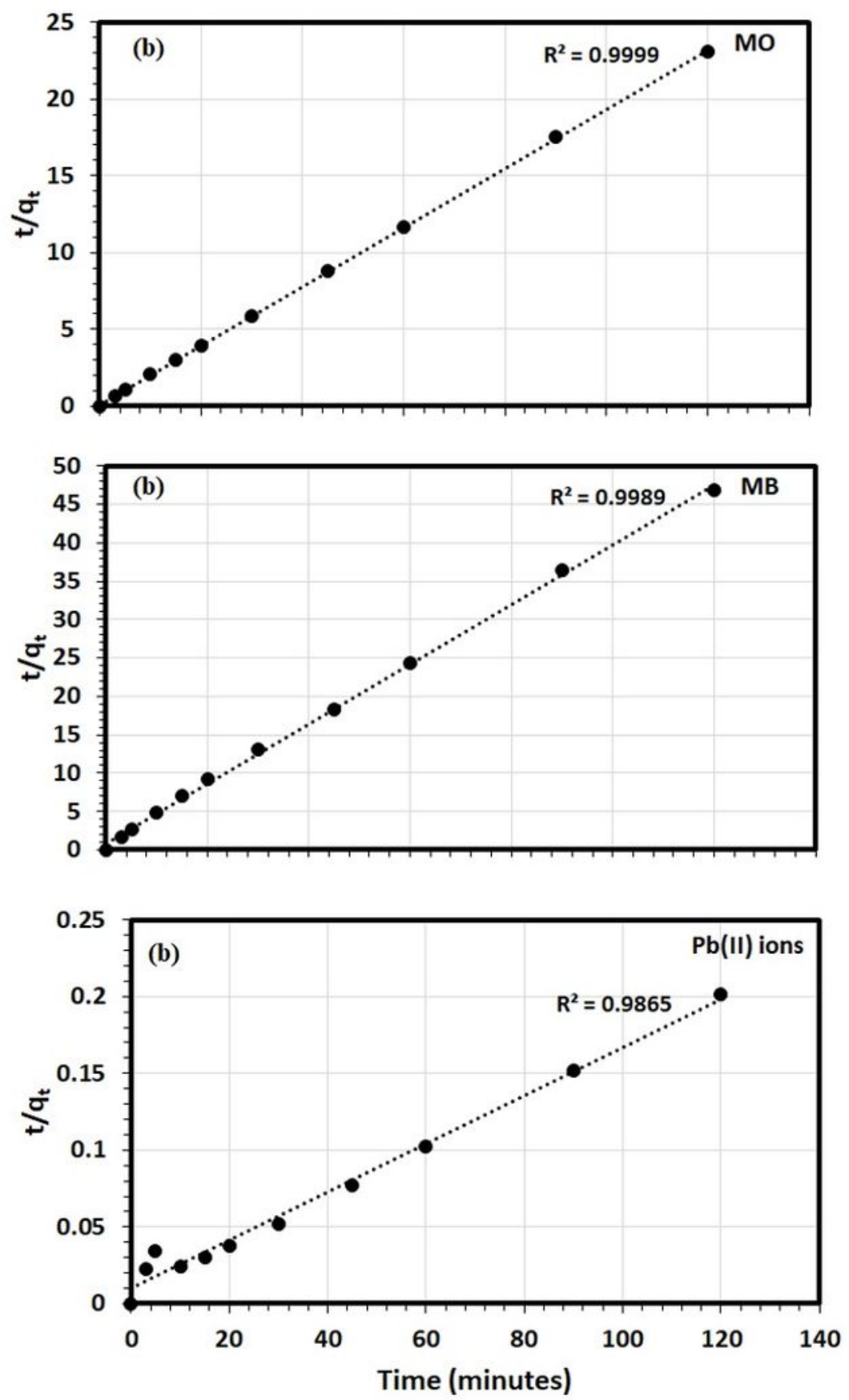

Figure 15

The application of PSO kinetic model for the removal of $\mathrm{MB}, \mathrm{MO}$ and $\mathrm{Pb}$ (II) by MWG ZnO NPs from model solution. (Experimental conditions: $20.0 \mathrm{ml}$ solution, pH 5.6, MWG ZnO NPs mass $15.0 \mathrm{mg}, 298 \mathrm{~K}$, and [MO] $5.0 \mathrm{mg} / \mathrm{L},[\mathrm{MB}] 5.0 \mathrm{mg} / \mathrm{L},[\mathrm{Pb}] 500.0 \mathrm{mg} / \mathrm{L})$. 

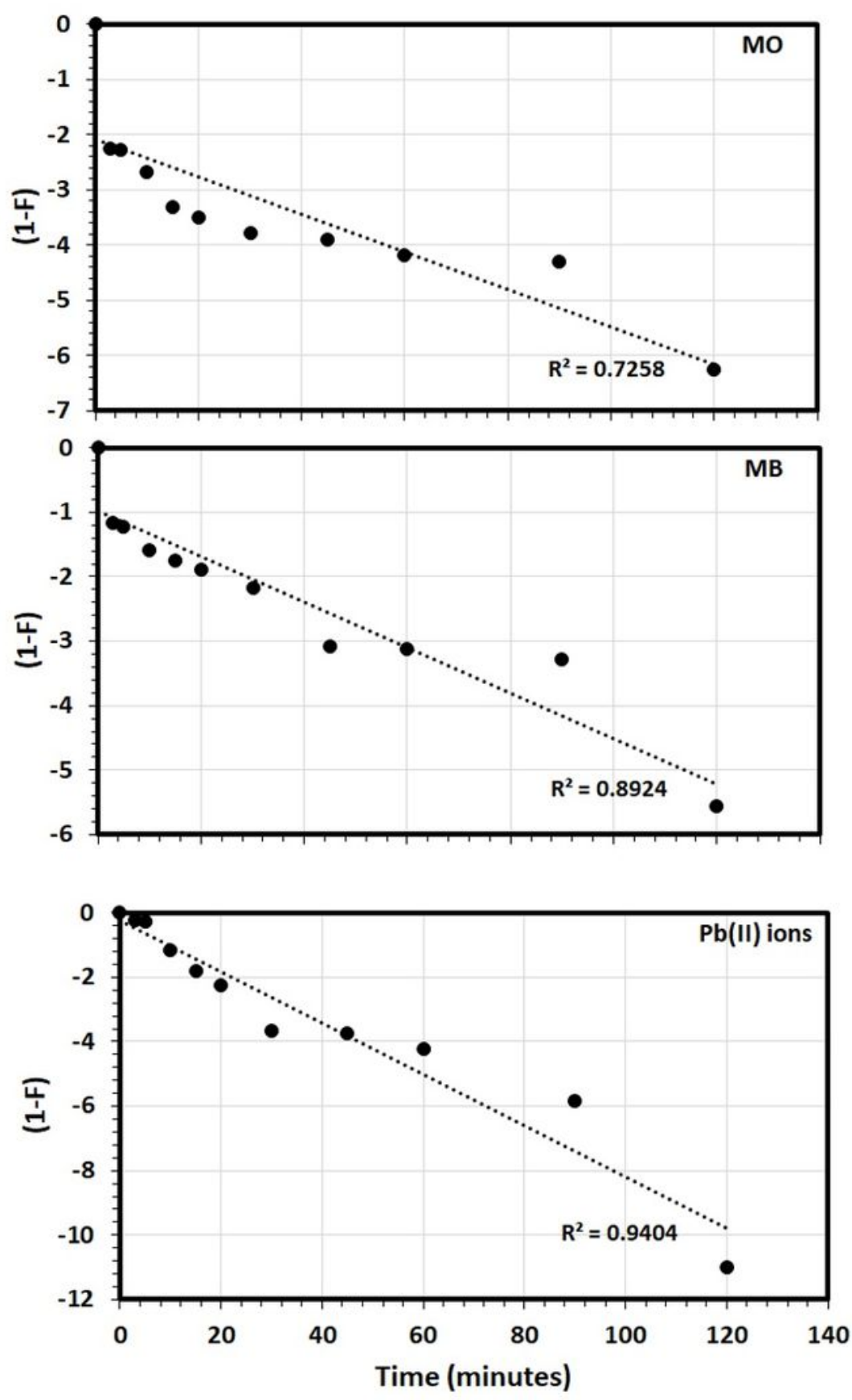

Figure 16

The application of LFD kinetic model for the removal of $\mathrm{MB}, \mathrm{MO}$ and $\mathrm{Pb}(\mathrm{II})$ by MWG ZnO NPs from model solution. (Experimental conditions: $20.0 \mathrm{ml}$ solution, pH 5.6, MWG ZnO NPs mass $15.0 \mathrm{mg}, 298 \mathrm{~K}$, and [MO] $5.0 \mathrm{mg} / \mathrm{L},[\mathrm{MB}] 5.0 \mathrm{mg} / \mathrm{L},[\mathrm{Pb}] 500.0 \mathrm{mg} / \mathrm{L})$. 

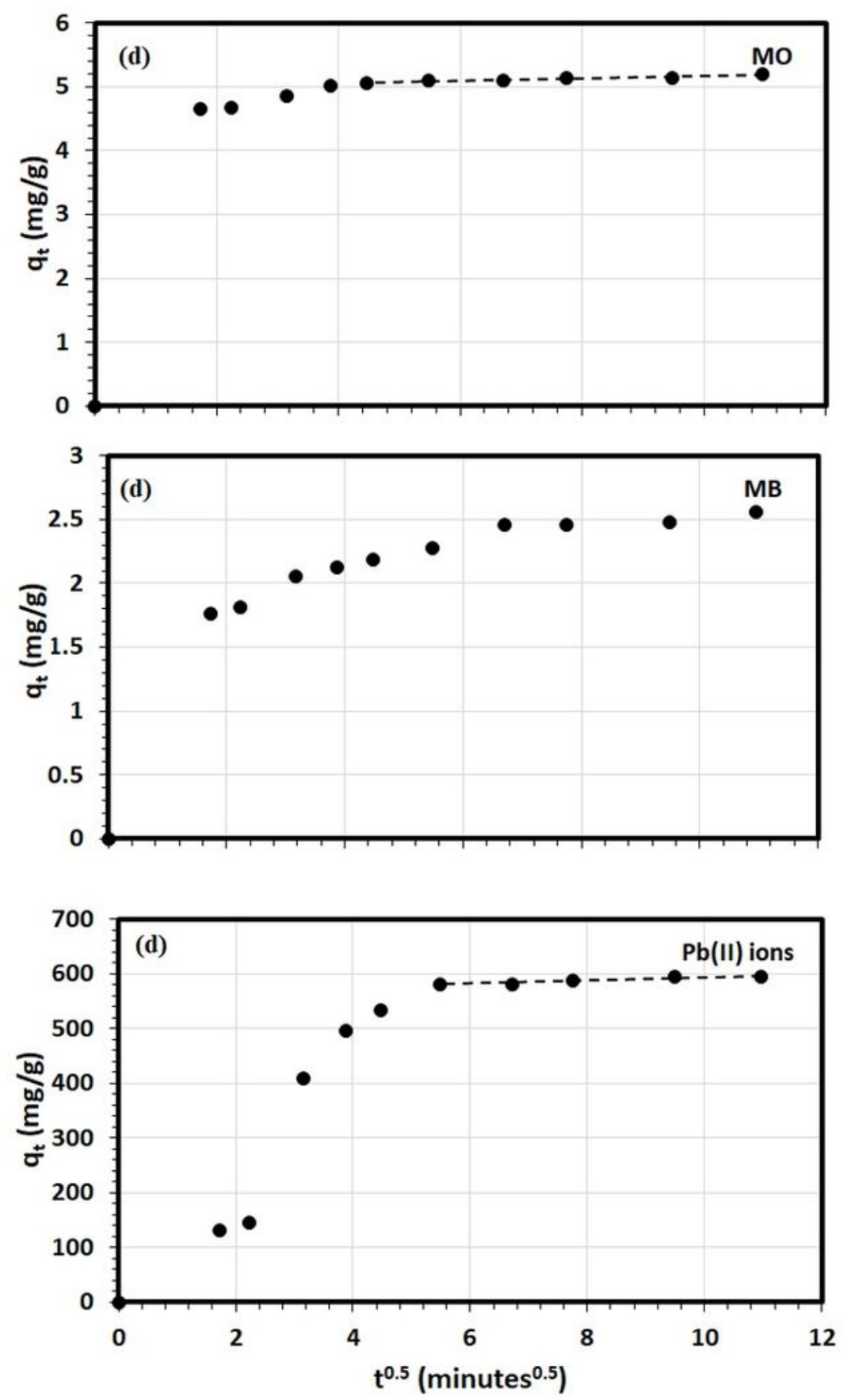

Figure 17

The application of IPD kinetic model for the removal of $\mathrm{MB}, \mathrm{MO}$ and $\mathrm{Pb}(\mathrm{II})$ by MWG ZnO NPs from model solution. (Experimental conditions: $20.0 \mathrm{ml}$ solution, pH 5.6, MWG ZnO NPs mass $15.0 \mathrm{mg}, 298 \mathrm{~K}$, and [MO] $5.0 \mathrm{mg} / \mathrm{L},[\mathrm{MB}] 5.0 \mathrm{mg} / \mathrm{L},[\mathrm{Pb}] 500.0 \mathrm{mg} / \mathrm{L})$. 


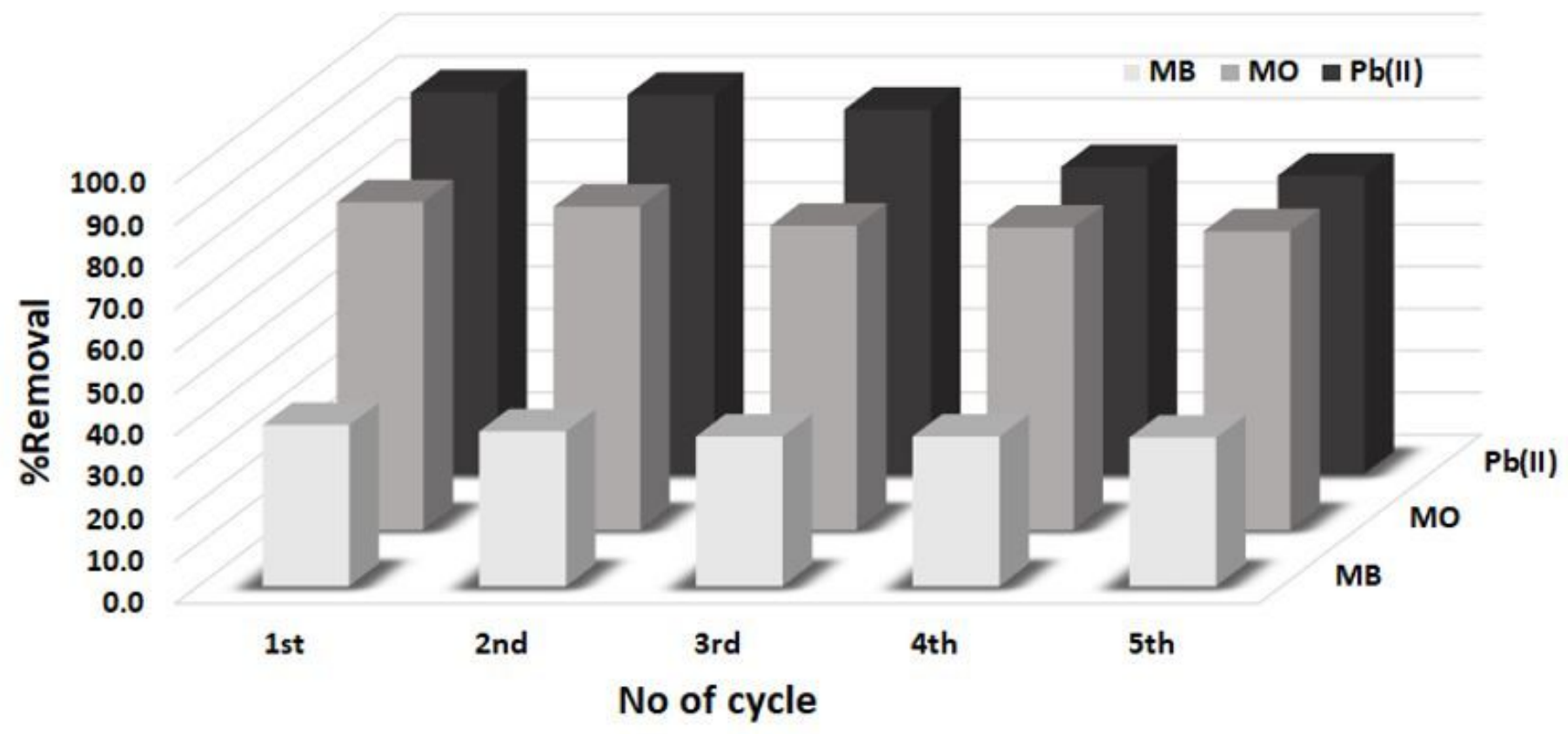

Figure 18

Recycle study for the removal of $\mathrm{MB}, \mathrm{MO}$ and $\mathrm{Pb}(\mathrm{II})$ by MWG ZnO NPs from model solution.

(Experimental conditions: $20.0 \mathrm{ml}$ solution, pH 5.6, MWG ZnO NPs mass $15.0 \mathrm{mg}$, $298 \mathrm{~K}$, and [MO] 5.0 $\mathrm{mg} / \mathrm{L},[\mathrm{MB}] 5.0 \mathrm{mg} / \mathrm{L},[\mathrm{Pb}] 500.0 \mathrm{mg} / \mathrm{L})$. 


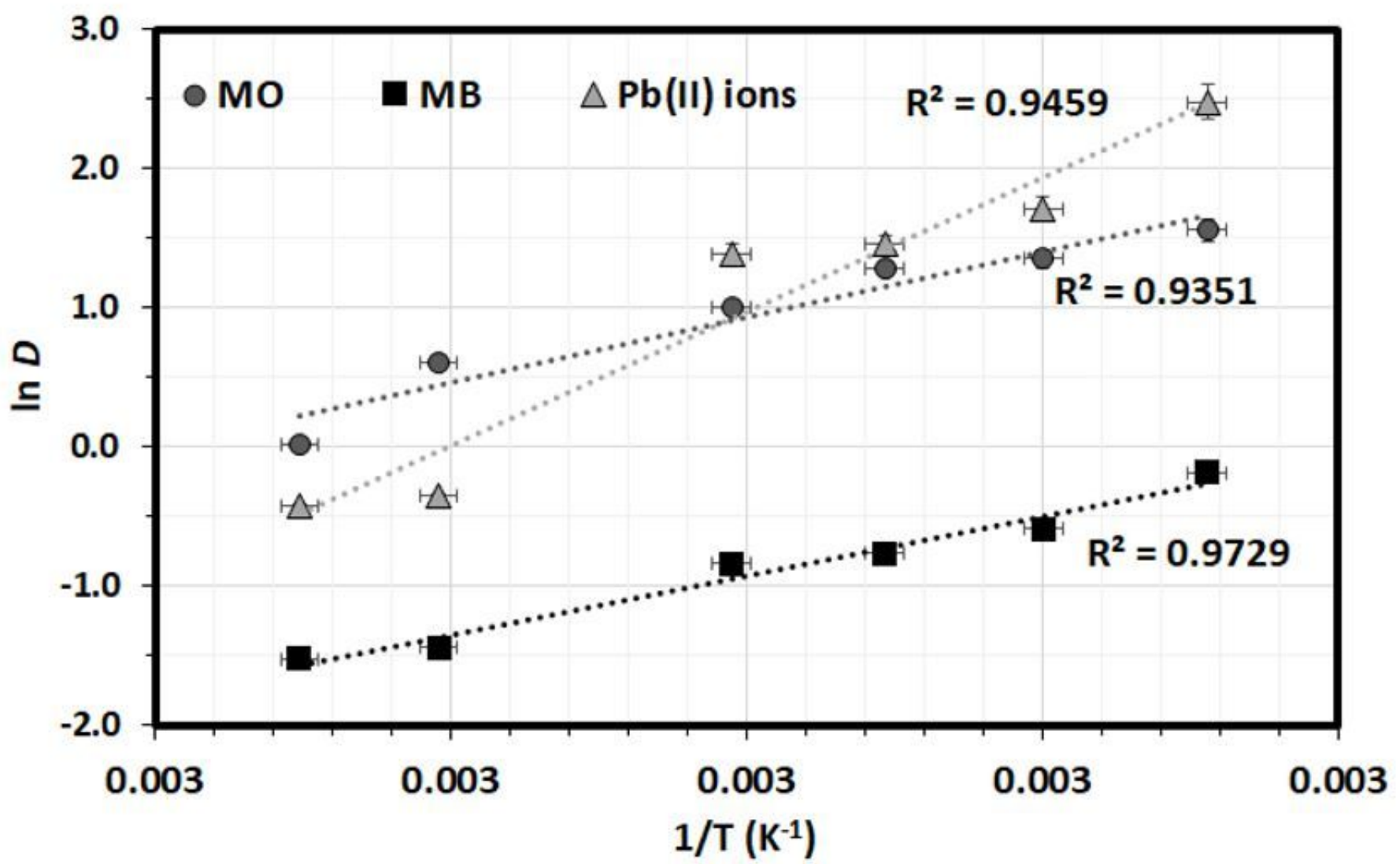

Figure 19

The estimation of thermodynamic parameters for $\mathrm{MO}, \mathrm{MB}$, and $\mathrm{Pb}$ (II) ions removal by the MWG ZnO NPs from model solution. (Experimental conditions: $20.0 \mathrm{ml}$ solution, pH 5.6, MWG ZnO NPs mass $15.0 \mathrm{mg}$, and [MO] $5.0 \mathrm{mg} / \mathrm{L}$, [MB] $5.0 \mathrm{mg} / \mathrm{L},[\mathrm{Pb}] 500.0 \mathrm{mg} / \mathrm{L})$. 